\title{
The cross-national epidemiology of specific phobia in the World Mental Health Surveys
}

\author{
Klaas J. Wardenaar ${ }^{1}$, Carmen C.W. Lim² ${ }^{2}$, Ali O. Al-Hamzawi ${ }^{3}$, Jordi Alonso ${ }^{4}$, Laura H. \\ Andrade $^{5}$, Corina Benjet ${ }^{6}$, Brendan Bunting ${ }^{7}$, Giovanni de Girolamo ${ }^{8}$, Koen Demyttenaere ${ }^{9}$, \\ Silvia E. Florescu ${ }^{10}$, Oye Gureje ${ }^{11}$, Tachi Hisateru ${ }^{12}$, Chiyi Hu ${ }^{13}$, Yueqin Huang ${ }^{14}$, Elie \\ Karam $^{15}$, Andrzej Kiejna ${ }^{16}$, Jean Pierre Lepine ${ }^{17}$, Fernando Navarro-Mateu ${ }^{18}$, Mark Oakley \\ Browne $^{19}$, Maria Piazza ${ }^{20}$, José Posada-Villa ${ }^{21}$, Margreet L. ten Have ${ }^{22}$, Yolanda Torres ${ }^{23}$, \\ Miguel Xavier ${ }^{24}$, Zahari Zarkov ${ }^{25}$, Ronald C. Kessler ${ }^{26}$, Kate M. Scott ${ }^{2}$, and Peter de Jonge ${ }^{1}$
}

${ }^{1}$ University of Groningen, University Medical Center Groningen, Department of Psychiatry, Interdisciplinary Center Psychopathology and Emotion Regulation (ICPE), Groningen, the Netherlands ${ }^{2}$ Department of Psychological Medicine, Dunedin School of Medicine, University of Otago, Dunedin, New Zealand ${ }^{3}$ College of Medicine, Al-Qadisiya University, Al Diwaniya City, Iraq ${ }^{4}$ Health Services Research Unit, Instituto Hospital del Mar de Investigaciones Médicas, Institut de Recerca Hospital del Mar, Barcelona, Spain ${ }^{5}$ Department/Institute of Psychiatry, University of São Paulo Medical School, São Paulo, Brazil ${ }^{6}$ Department of Epidemiologic and Psychosocial Research, National Institute of Psychiatry Ramón de la Fuente, Mexico City, Mexico ${ }^{7}$ Psychology Research Institute, Ulster University, Londonderry, United Kingdom ${ }^{8}$ IRCCS Centro S. Giovanni di Dio Fatebenefratelli, Brescia, Italy ${ }^{9}$ Department of Psychiatry, University Hospital Gasthuisberg, Katholieke Universiteit Leuven, Leuven, Belgium ${ }^{10}$ National School of Public Health, Management and Professional Development, Bucharest, Romania ${ }^{11}$ Department of Psychiatry, College of Medicine, University of Ibadan, University College Hospital, Ibadan, Nigeria ${ }^{12}$ National Institute of Mental Health, National Center for Neurology and Psychiatry, Japan ${ }^{13}$ Shenzhen Institute of Mental Health and Shenzhen Kangning Hospital, Guangdong Province, PR China ${ }^{14}$ Institute of Mental Health, Peking University, Beijing, China ${ }^{15}$ St George Hospital University Medical Center, Balamand University, Institute for Development, Research, Advocacy, Beirut, Lebanon ${ }^{16}$ Department of Psychiatry Wroclaw Medical University, Wroclaw, Poland ${ }^{17}$ Hôpital Lariboisière Fernand Widal, Assistance Publique Hôpitaux de Paris INSERM UMR-S 1144, University Paris Diderot and Paris Descartes Paris, France ${ }^{18}$ Instituto Murciano de Investigación Biosanitaria (IMIB)-Arrixaca. Centro de Investigación Biomédica en Red. Epidemiología y Salud Pública (CIBERESP)-Murcia. Subdirección General de Salud Mental y Asistencia Psiquiátrica. Servicio Murciano de Salud, El Palmar (Murcia), Spain ${ }^{19}$ Department of Psychiatry, Monash University, Australia ${ }^{20}$ National Institute of Health, Peru, Universidad Cayetano Hereidia, St Martin de Porres, Peru ${ }^{21}$ El Bosque University, Bogota, Colombia ${ }^{22}$ Trimbos Instituut, Netherlands Institute of Mental Health and Addiction, Utrecht, Netherlands ${ }^{23}$ Center for Excellence on Research in Mental Health, CES University, Medellin, Colombia ${ }^{24}$ Nova faculdade ciencias medicas, Faculdade de

Corresponding author: Klaas J. Wardenaar PhD, Interdisciplinary Center Psychopathology and Emotion Regulation, University Medical Center Groningen, P.O. box 30.001, 9700RB Groningen, the Netherlands. k.j.wardenaar@umcg.nl.

Conflict of interest

The other authors report no disclosures. 
Ciências Médicas, Universidade Nova de Lisboa, Lisboa, Portugal ${ }^{25}$ Directorate Mental Health, National Center of Public Health and Analyses, Sofia, Bulgaria ${ }^{26}$ Department of Health Care Policy, Harvard University Medical School

\section{Abstract}

Background-Although specific phobia is highly prevalent, associated with impairment, and an important risk factor for the development of other mental disorders, cross-national epidemiological data are scarce, especially from low and middle-income countries. This paper presents epidemiological data from 22 low, lower-middle, upper-middle and high-income countries.

Method-Data came from 25 representative population-based surveys conducted in 22 countries (2001-2011) as part of the World Health Organization World Mental Health Surveys initiative $(\mathrm{N}=124,902)$. The presence of specific phobia as defined by the Diagnostic and Statistical Manual of Mental Disorders, fourth edition was evaluated using the World Health Organization Composite International Diagnostic Interview.

Results-The cross-national lifetime and 12-month prevalence rates of specific phobia were, respectively, $7.4 \%$ and $5.5 \%$, being higher in females $(9.8 \%$ and $7.7 \%)$ than in males $(4.9 \%$ and $3.3 \%$ ) and higher in high and higher-middle income countries than in low/lower-middle income countries. The median age of onset was young ( 8 years). Of the 12-month patients, $18.7 \%$ reported severe role impairment (13.3\%-21.9\% across income groups) and $23.1 \%$ reported any treatment (9.6\%-30.1\% across income groups). Lifetime comorbidity was observed in $60.2 \%$ of those with lifetime specific phobia, with the onset of specific phobia preceding the other disorder in most cases (72.6\%). Interestingly, rates of impairment, treatment-use and comorbidity increased with the number of fear subtypes.

Conclusion-Specific phobia is common and associated with impairment in a considerable percentage of cases. Importantly, specific phobia often precedes the onset of other mental disorders, making it a possible early-life indicator of psychopathology vulnerability.

\section{Keywords}

specific phobia; epidemiology; comorbidity; cross-national; impairment; treatment

\section{Introduction}

Specific phobia is one of the most common mental disorders in the general population with lifetime and 12-month prevalence estimates in representative population surveys ranging from $7.7 \%$ to $12.5 \%$ and from $2.0 \%$ to $8.8 \%$, respectively (Kessler et al., 1994; 2005; Bijl et al., 1998; de Graaf et al., 2012; Stinson et al., 2007; Alonso et al., 2004; Grenier et al., 2011; Wells et al., 2006). In addition, prospective studies have shown high incidence rates for specific phobia. Angst et al. (2016) found a cumulative incidence of $26.9 \%$ between ages 20 and 50 years. Bijl et al. (2002) found a 1-year incidence rate of 2.20 new cases per 100 person-years. Grant et al. (2009) found a lower 1-year incidence rate of 0.44 new cases per 100 person-years. Interestingly, prevalence rates (e.g. Kessler et al., 1994; Bijl et al., 1998; Stinson et al., 2007) and incidence rates (Bijl et al., 2002; Angst et al., 2016) have been 
found to be higher in females than in males. Also, prevalence rates have been shown to decrease with age (e.g. Stinson et al., 2007; Sigström et al., 2016).

Because of its high prevalence, lifetime persistence (e.g. Goisman et al., 1998), associated impairment and high lifetime comorbidity rate with other disorders, specific phobia is important from both an epidemiological and a clinical perspective. Previous work has shown considerable role impairment in those with specific phobia, with $34.2 \%$ reporting significant role impairments in their daily life, compared to $26.5 \%$ in agoraphobia and $33.5 \%$ in social phobia (Magee et al., 1996). Depla et al. (2008) showed that up to $59.2 \%$ of patients reported interference with their daily life. Using data from the National Epidemiologic Survey on Alcohol and Related Conditions (NESARC), Stinson et al. (2007) showed that impairment levels in specific phobia were comparable with other anxiety- and substance-use disorders. However, other studies have found low disability in specific phobia compared to other disorders (e.g. Wells et al., 2006; Ormel et al., 2008) and it has been suggested that observed functional impairment in specific phobia can be partly explained by high cooccurrence with other disorders (Comer et al., 2011). Nevertheless, the restricted lifestyle resulting from fear and avoidance in specific phobia is likely to contribute independently to functional impairment.

Previous surveys have shown that comorbidity rates between specific phobia and other mental disorders are high (Kessler et al., 1996; 1997), with estimated rates of up to $81.0 \%$ (Magee et al., 1996). Interestingly, these retrospective studies showed that in the majority of comorbid cases, the onset of specific phobia precedes the other disorder(s) (Magee et al., 1996; Kessler et al., 1996; 1997). Prospective work has shown that specific phobia is associated with a higher odds of later depressive, anxiety and eating disorders (Goodwin et al., 2002; Bittner et al., 2004; Trumpf et al., 2010; Lieb et al., 2016) but not of later substance-use disorders (Zimmermann et al., 2003). Grant et al. (2009) showed that specific phobia at baseline was associated with an increased incidence of other anxiety disorders. However, these associations could also be explained by other baseline disorders and sociodemographic factors.

Relatively effective treatments, such as behavior therapy and cognitive therapy are available for specific phobia (Choy et al., 2007). However, despite specific-phobia patients' need for care, only a minority of patients seeks treatment in their lifetime (Stinson et al., 2007: 8.0\%; Magee et al., 1996: 46.6\%). In addition it has been shown that specific phobia patients that do seek treatment take much longer to do so compared to other anxiety disorders (Ten Have et al., 2013; Iza et al., 2013).

Within specific phobia, the DSM distinguishes between different subtypes: animal (e.g. bugs, snakes), natural environment (e.g. heights, weather), blood-injection-injury, situational (e.g. flying on a plane, enclosed spaces) and other (e.g. vomiting, choking). Previously phobia subtypes have been shown to differ in terms of e.g. prevalence, impairment levels and comorbidity rates (e.g. Frederikson et al., 1996; Becker et al., 2007; Depla et al., 2008; Lebeau et al., 2011). Also, most patients have more than one subtype (Curtis et al., 1998; Burstein et al., 2012) and increasing numbers of subtypes have been shown to be associated 
with more comorbidity, impairment and treatment-seeking (e.g. Curtis et al., 1998; Stinson et al., 2007; Burstein et al., 2012).

Although the above described findings indicate that specific phobia a highly relevant condition that deserves attention from both researchers and clinicians, they all come from surveys in western, high income countries. This makes it hard to judge the universal relevance of specific phobia as an impairing condition and a marker for increased psychopathology risk. In this study we therefore took a cross-national approach, combining World Mental Health (WMH) population survey data from 22 low/lower-middle income, upper-middle income and high-income countries $(n=124,902)$ to gain a more complete insight into the epidemiological characteristics of specific phobia around the world.

\section{Method}

\section{Sample}

Data came from 25 World Health Organization (WHO) WMH surveys, conducted in 22 countries (Appendix Table 1). Of these countries, five are classified by the World Bank (World Bank, 2008) as low-income/lower-middle income (Colombia, Iraq, Nigeria, Peru and the Peoples Republic of China [PRC]), six as upper-middle income countries (Brazil, Bulgaria, Colombia [Medellin], Lebanon, Mexico and Romania) and twelve as high income countries (Belgium, France, Germany, Italy, Japan, Netherlands, New Zealand, Northern Ireland, Poland, Portugal, Spain and the USA). The sample sizes of the surveys ranged from 2,357 (Romania) to 12,790 (New Zealand) and the total combined sample size was 124,902. Most surveys were based on nationally representative stratified multistage clustered area probability samples of household residents. All respondents were 18 years or older. Response rates ranged from $45.9 \%$ (France) to $97.2 \%$ (Colombia) and the average weighted response rate across countries was $69.3 \%$. The surveys were conducted face-to-face by trained lay interviewers. The same standardized procedures for interviewer training, translation of the used study materials and quality control were used in all countries (Kessler \& Üstün, 2008)]. To reduce the burden of the interview it was often divided into two parts. In Part I, core mental disorders were assessed. In Part II, additional disorders and correlates were assessed. All respondents completed part I $(n=124,902)$. Part II $(n=60,345)$ was additionally administered to a subsample of respondents meeting criteria for any Part I disorder and in a probability subsample of the other part I respondents. Part II responses were weighted by the inverse of their probability of selection into the part II sample to adjust for any differential sampling. All respondents provided informed consent prior to the interview and the study protocols were approved by the institutional review boards of the organizations coordinating the surveys.

\section{Measures}

Diagnostic assessments-The lifetime and 12-month prevalence and $\mathrm{AOO}$ of specific phobia as defined in the Diagnostic and Statistical Manual, fourth edition was evaluated with the World Health Organization Composite International Diagnostic Interview (CIDI). In the screening section, respondents were shown a list of six specific fears (animals, still water/ weather events, blood/injuries/medical experiences [BIM], closed spaces, high places, 
flying) and were asked if they ever had a strong fear of any of these things. If any specific fear was reported in the screening section, the specific phobia section was administered. The CIDI was also used to assess other psychiatric disorders, including mood (major depressive, dysthymic, bipolar-I, bipolar-II and sub-threshold bipolar disorder) anxiety (agoraphobia, social phobia, generalized anxiety, panic, post-traumatic stress and separation anxiety) substance use (alcohol and drug abuse, alcohol and drug dependence with abuse) and behavior disorders (attention-deficit/hyperactivity, oppositional-defiant, conduct, intermittent explosive disorder). The WMH interview translation, back-translation and harmonization was done by culturally competent bilingual clinicians, who reviewed, modified, and approved the key phrases describing the assessed symptoms (Harkness et al., 2008). Masked clinical reappraisal with a standardized clinical interview showed fair agreement for specific phobia (area under the receiver operating curve $=0.67$; Haro et al., 2006).

Healthcare use-The services module of the WMH-CIDI v3.0 (Kessler \& Üstün, 2004) was used to assess if respondents ever received treatment for emotion regulation problems, psychological distress, anxiety, or substance use. If respondents reported ever receiving such care, follow-up questions were asked about their age at the first and last treatment and about the treatment they received in the past 12 months. Different sectors of treatment were distinguished. The specialty mental health sector included psychiatrists, psychologists or any other non-psychiatrist mental health specialists (social workers, counselors in specialty mental health settings, mental health helplines, overnight hospital admissions for mental health or substance-related problems). The general medical sector included general practitioners, other medical doctors, nurses, occupational therapists or any other healthcare professional. The human services sector included religious or spiritual advisors, social workers or counsellors in other settings than the specialty mental health sector. The complementary and alternative medicine (CAM) sector included any other type of healer (e.g. herbal healers, self-help groups).

Impairment-A modified version of the Sheehan Disability Scales (SDS; Leon et al., 1997) was used to assess 12-month role-functioning. Respondents were asked to remember the month in which their specific phobia was most severe and to rate its interference with functioning in four domains (home management, ability to work, relationships and social life) on a 10-point scale. Those with a score of 7 or higher on one or more SDS-domains were classified as severely impaired. Respondents with 12-month specific phobia were also asked how many of the 365 days in the past 12 months they had been totally unable to work or carry out their normal activities because of their specific phobia.

Demographic factors-The following demographic factors were investigated: age-group (18-29 years, 30-44 years, 45-59 years and 60+ years), gender, employment status (employed, student, homemaker, retired, other [unemployed, temporarily laid off, maternity leave, illness/sick leave, and disabled]), marital status (currently married, divorced/ separated/widowed, never married), education level (no education, some primary, finished primary, some secondary, finished secondary, some college, finished college) and household income (low, low-average, high-average and high). Income categories were based on the quartiles of country-specific gross household income distributions (Levinson et al., 2010). 
Statistical analyses-Analyses of prevalence, AOO and impairment were carried out for the cross-national sample, each country-income group, each country survey, and crossnational gender-groups. Cross-tabulations were used to estimate the lifetime, 12-month and 30-day prevalence. Only lifetime prevalence rates were calculated for subtypes of specific phobia and the prevalence of specific phobia with 1 to $\geq 4$ lifetime subtypes.

The 12-month prevalence of specific phobia among lifetime cases was used as an indicator of recurrence or chronicity: e.g. a disorder can have a high lifetime prevalence, but a low level of recurrence as shown by a low 12-month prevalence among lifetime cases. The 30day prevalence among 12-month cases was calculated as an indicator of disorder duration: e.g. a disorder can have a high 12-month prevalence, but a limited duration, as shown by a low 30-day prevalence. The percentages of lifetime and 12-month comorbidity in lifetime cases and the percentages of 12-month comorbidity in 12-month cases were estimated. In addition, the percentages of cases in which specific phobia was the temporally primary disorder were calculated. The percentages of 12-month specific phobia cases with severe role impairment and healthcare use across sectors were calculated with cross-tabulation. The mean number of days out of role was calculated for all 12-month specific phobia cases combined and for subsamples of 12-month cases, split out by their highest reported domain of role-impairment. Percentages of lifetime comorbidity, 12-month impairment and healthcare-use were calculated for each subtype and groups with 1 to $\geq 4$ lifetime subtypes.

The $\mathrm{AOO}$ and the projected risk at age 75 were estimated with the two-part actuarial method implemented in SAS. The actuarial method assumes a constant conditional risk of onset in a given year of life across cohorts and allows for accurate estimations of the onset timings within a year (Halli et al., 1992). Associations of lifetime specific phobia with demographic factors were analyzed with survival models, adjusted for age cohort, gender, person-years and country. Associations of 30-day specific phobia with demographic factors were analyzed with logistic regression models, adjusted for time since specific phobia onset, AOO, gender and country. Associations of demographic factors with recurrence (12-month prevalence among lifetime cases) and duration (30-day prevalence among 12-month cases) were analyzed with logistic regression, adjusted for time since specific phobia onset, AOO, gender and country. The distributions of AOO and of sociodemographic were calculated for groups with different subtypes and subgroups with 1 to $\geq 4$ lifetime subtypes.

All analyses were weighted to adjust for differential selection probabilities within households, to match the samples to population sociodemographic distributions and to adjust for nonresponse (Kessler \& Üstün, 2008). Design-adjusted standard errors were estimated using the Taylor series linearization method (Wolter, 1985), implemented in SAS 9.4 (SAS Institute Inc., Cary, North Carolina). Design-adjusted Wald $\chi^{2}$-tests were used to test the multivariate statistical significance of sets of predictors.

\section{Results \\ Prevalence}

Lifetime specific phobia prevalence ranged from $2.6 \%$ to $12.5 \%$ across countries (Table 1) and the averaged cross-national lifetime prevalence in was $7.4 \%$ for the whole sample 
(median $=6.8 \%$; IQR $=4.8 \%-10.2 \%$ ), $4.9 \%$ for the male and $9.8 \%$ for the female subsample. The prevalence was $8.0-8.1 \%$ in high income and upper-middle income countries and 5.7\% in the low-lower middle income countries. The overall mean 12-month prevalence was 5.5\% in the whole sample (median $=5.0 \%$; $\mathrm{IQR}=3.8 \%-7.6 \%$ ), $3.3 \%$ among males and $7.7 \%$ among females. The 12-month prevalence differed across countries (1.7\%-10.6\%) and income groups $(4.0 \%-6.4 \%)$, with the lowest prevalence in the low-lower middle income group $(4.0 \%)$. The overall mean 30-day prevalence was $3.9 \%$ in the total sample, with differences across gender (males: $2.1 \%$; females: $5.5 \%$ ), countries (1.0\%-8.8\%) and income groups $(2.4 \%-4.8 \%)$, with the lowest prevalence $(2.4 \%)$ in the low-lower middle income countries.

Of specific phobia subtypes (Table 2), animal fear had the highest cross-national lifetime prevalence (3.8\%), followed by BIM (3.0\%), high places (2.8\%) and still water or weather events fear $(2.3 \%)$. Fear of flying had the lowest prevalence $(1.3 \%)$. The low-lower middle income countries showed the lowest prevalence rates for all subtypes $(0.6 \%-1.6 \%)$ and considerably higher prevalence rates in upper-middle income countries $(1.2 \%-4.4 \%)$ and high income countries (1.7\%-3.7\%). The clearest difference was seen for fear of flying, which had an almost three times higher prevalence in high income (1.7\%) than in low-lower middle income $(0.6 \%)$ countries. All subtypes were most common in females. Of the crossnational sample, $3.4 \%$ reported a single subtype, $1.8 \%$ reported two subtypes, $1.1 \%$ reported three subtypes and $1.1 \%$ reported $\_4$ subtypes. Higher numbers of subtypes were more common among females than males.

\section{Recurrence and duration}

The averaged prevalence of 12-month specific phobia among lifetime specific phobia cases was $74.2 \%$ for the whole cross-national sample (median $=73.0 \%, \mathrm{IQR}=70.2 \%-81.3 \%$; Table 1). The averaged prevalence of 30-day specific phobia among 12 -month cases was $70.2 \%$ for the cross-national sample (median $=72.6 \%, \mathrm{IQR}=67.6 \%-78.3 \%$ ). Both prevalence-rates were higher in females than in males. In addition, the 30-day prevalence among 12-month cases was the only that differed notably across income groups, with the lowest rate in the low-low middle income group (58.7\%).

\section{$\mathrm{AOO}$}

The median AOO was 8 years (IQR=5-13; Appendix Table 2) and differed slightly across surveys (IQR $=8-9$ years). The cross-national projected risk at age 75 was only $0.7 \%$ higher than the observed lifetime prevalence rate $(8.1 \%$ vs. $7.4 \%)$, reflecting specific phobia's young AOO distribution. Early AOO was most common for all subtypes, but especially common for fear of still water/weather (Table 3; 37.1\%), animals (36.6\%), and closed spaces (35.2\%). A slightly older onset distribution was seen for fear of flying and high places. Early onset rates increased and late onset rates decreased with the number of fears.

\section{Comorbidity}

In $60.5 \%$ of lifetime specific phobia cases, at least one other lifetime disorder was present, with $34.3 \%$ having a comorbid mood disorder, $41.2 \%$ an anxiety disorder, $15.9 \%$ a substance-use disorder, and $17.4 \%$ an impulse-control disorder (Table 4). In those with 12month comorbidity of specific phobia with any other disorder, comorbid anxiety disorders 
were most common (29.6\%), followed by mood disorders (21.0\%). Specific phobia preceded the other disorders in the majority of comorbid cases (71.6\%-92.2\%). Lifetime comorbidity with any other disorder ranged from $60.6 \%$ to $73.0 \%$ across subtypes (Table 3 ). Comorbidity was highest with anxiety (range: $41.1 \%-58.8 \%$ ) and mood disorders (range: $34.7 \%-43.6 \%$ ). Comorbidity rates were highest in those with fear of closed spaces and flying and increased with the number of subtypes from $49.7 \%$ (one subtype) to $82.1 \%$ ( $\geq 4$ subtype).

\section{Demographic correlates of specific phobia onset}

In the combined sample, higher risk of lifetime onset of specific phobia (Table 5) was observed in respondents aged younger than 60 compared to respondents aged 60 and older $(\mathrm{OR}=1.5-1.8)$, in women compared to men $(\mathrm{OR}=2.0)$, in homemakers and those with 'other' employment status compared to employed respondents $(\mathrm{OR}=1.2-1.4)$, in previously-married compared to currently married $(\mathrm{OR}=1.2)$, in those with some college or less education compared to those who completed college $(\mathrm{OR}=1.3-1.7)$, and in those with low and lowaverage income compared to those with a high income $(\mathrm{OR}=1.1-1.2)$. When analyzed per income group (Appendix Tables 3-5), the following associations with increased odds of lifetime specific phobia onset were consistently observed: being in the youngest age-cohort $(\mathrm{OR}=1.3-2.0)$, being female $(\mathrm{OR}=1.5-2.3)$, having employment status 'other' $(\mathrm{OR}=1.3-$ $1.5)$, and having a lower education than finished college ( $\mathrm{OR}=1.2-1.9)$.

The age-group distribution varied across subtypes (Table 3), with most young persons in animal and BIM phobia. The percentage of females was highest in all subtype groups and increased with number of subtypes. Employment status showed limited variation across subtypes, but the percentage of working persons was markedly lower (53.1\%) in those with $\geq 4$ subtypes compared to those with 1-3 subtypes (57.7\%-60.8\%). The percentages of cases with completed college showed some variation across subtypes (8.8\%-12.8\%), but a more striking difference between those with $\geq 4$ subtypes (7.6\%) and those with 1-3 subtypes (12.1\%-13.8\%). Income-group distributions showed limited variation across subtypes, but the percentages of low- and low-mid income increased with the number of subtypes.

\section{Demographic correlates of persistence}

12-month specific phobia prevalence among lifetime cases (Table 5) was higher in those with early AOO compared to those with late $\mathrm{AOO}(\mathrm{OR}=1.4)$, in women compared to men $(\mathrm{OR}=1.8)$, in those who were retired or had employment status 'other' compared to the employed ( $\mathrm{OR}=1.3$ and $\mathrm{OR}=1.5)$, in those with some college or less compared to those with finished college ( $\mathrm{OR}=1.3-1.7)$, and in those with low income compared to those with high income $(\mathrm{OR}=1.4)$. Only female gender was consistently observed to be associated with an increased odds of 30-day prevalence among 12-month cases ( $\mathrm{OR}=1.5-1.9$; Appendix Tables $3-5)$.

\section{Impairment}

In the combined sample, $18.7 \%$ of 12 -month specific phobia cases reported severe role impairment in any domain (Appendix Table 6), with the highest percentage of severe impairment in the home domain (10.3\%) and the lowest in the relationship domain (7.9\%). The percentages of severe impairment differed across income groups on all domains, except 
for work. The low-lower middle income group, especially Nigeria and PRC Shen Zhen, showed the lowest percentages of severe impairment. The upper-middle income group showed the highest percentages of severe impairment (range: 9.9-14.4\%). The mean number of days out of role in the past year due to 12-month specific phobia was 12.2 ( $\mathrm{SE}=0.9$ ). However, those with severe impairment in any domain reported 29.1 days out of role (Appendix Table 7), with the number of days varying depending on the investigated domain of impairment (34.6-47.9). The percentage of cases reporting any impairment varied somewhat across subtypes (52.1\%-57.3\%; Table 3). However, impairment rates increased with the number of fear subtypes, with $11.6 \%$ reporting severe impairment in those with one subtype and $20.6 \%$ in those with $\geq 4$ subtypes.

\section{Treatment}

Cross-nationally, the percentage of 12-month specific phobia cases reporting any treatment was $23.1 \%$. Treatment was more common in those reporting severe impairment (32.5\%) compared to those reporting mild or moderate impairment (respectively, $21.1 \%$ and $22.8 \%$; Appendix Table 8). Treatment rates differed across income groups, with $9.6 \%$ in low-lower middle income, $16.0 \%$ in higher middle income, and $30.1 \%$ in high income countries. Overall treatment use showed some variation across subtypes (Table 3), with the highest rates for fear of flying (28.4\%), closed spaces (27.5\%), and high places (26.0\%). Also, rates of treatment use increased from $16.7 \%$ in those with one subtype to $29.7 \%$ in those with $\geq 4$ subtypes.

\section{Discussion}

Specific phobia is a common mental disorder with a cross-national lifetime prevalence of $7.4 \%$. Interestingly, the prevalence, impairment and duration of specific phobia were considerably higher in high- and upper-middle income countries than in low-lower middle income countries. This could be due to cultural differences in the degree to which symptoms of specific phobia are recognized or attributed to a mental disorder and differences in catastrophic cognitions about phobic/anxious symptoms (Hinton \& Pollack, 2009; Marques et al., 2011; Hofmann \& Hinton, 2014). Also, there could be differences in how interview questions are interpreted, social norms, attitudes, and stigmas surrounding mental problems (Angermeyer \& Dietrich, 2006; Lee et al., 2009). For instance, differences in specific phobia duration could be attributed to the reasons above but could also reflect differences in the kinds and/or frequencies of reported phobic stimuli. Although cross-national differences could not be investigated in-depth, the results suggest that the phenomenology and underlying processes of specific phobia vary across countries. As observed previously (e.g. Stinson et al., 2007; Lebeau et al., 2010), females showed higher specific-phobia prevalence than males.

Young age was also observed to be associated with specific phobia, aligning with previous work (Stinson et al., 2007; Sigström et al., 2016). Those with lower education had higher odds of specific phobia, which has been observed previously (Magee et al., 1996) but not in all surveys (Stinson et al., 2007). Those with employment-status 'Other' (e.g. disabled, 
looking for job) showed higher odds of specific phobia. Magee et al (1996) found a similar association, but it has not been investigated in other surveys.

Subtype-specific analyses showed that animal phobia had the highest cross-national prevalence $(3.0 \% ; 1.4-8.7 \%$ across countries), in line with previous observations (3.3\%7.0\%; Lebeau et al., 2010; Curtis et al., 1998; Depla et al., 2008). Fear of still water or weather events had a prevalence of $2.3 \%$, aligning with previously reported prevalence rates for 'water' phobia (2.2-3.4\%) and 'storm' phobia (2.0-2.9\%; Lebeau et al., 2011). For fear of heights, the cross-national prevalence $(2.8 \%)$ was somewhat lower than reported previously (3.1-5.3\%; Lebeau et al., 2011). The cross-national prevalence of BIM phobia $(3.0 \%)$ was in line with previously estimated prevalence rates (3.2-4.5\%; Lebeau et al., 2011). The cross-national prevalence rates fear of closed spaces $(2.2 \%)$ and fear of flying $(1.3 \%)$ were both lower than reported previously (closed spaces: $3.2 \%-3.3 \%$; flying: $2.5 \%-$ 2.9\%; Lebeau et al., 2010). Apart from methodological differences, some of the discrepancies between current and previous findings could be explained by variations across countries in culture (see above) and rates of exposure (e.g. flying is less common in lowincome countries). Investigation of subtype co-occurrence showed that more than half of patients had two or more lifetime fear subtypes and that those with more subtypes had more severe clinical characteristics (e.g. impairment, comorbidity), aligning with previous results (e.g. Curtis et al., 1998).

The median AOO of specific phobia was found to be young, showing relatively limited variation across surveys ( $\mathrm{IQR}=5-13$ years). In line with this, the projected lifetime risk was only slightly higher than the observed lifetime prevalence rates (range of absolute differences across surveys: $0.1 \%-1.2 \%$; range of proportional differences across surveys: 1.7\%-22.0\%). In line with previous work (e.g. Burstein et al., 2012), the AOO distribution showed some differences across subtypes, with more early AOO for animal and natural phenomena phobias. The observation of a younger AOO distribution in those with multiple fear subtypes also aligns with previous work (Burstein et al., 2012). Lifetime comorbidity levels in specific phobia were high $(60.5 \%)$, with some subtypes being associated with higher levels than others. In the majority of comorbid cases, specific phobia onset preceded the other disorders(s). In addition, comorbidity became more common with increasing numbers of fear subtypes. Together, these results support the idea that specific phobia is an early-life indicator of psychopathology vulnerability.

Severe role impairment was reported in roughly a fifth of 12-month specific phobia cases, but reported impairment was lower in low-lower middle income countries than in the other countries. The mean number of days out of role in all subjects with 12-month specific phobia was 12.2 , but in respondents reporting severe impairment, this number was much higher, often in excess of a month, depending on the domain of severe impairment. 12month impairment increased with the number of reported fear subtypes, aligning with the idea that the presence of multiple lifetime fears marks increased clinical severity. Together, these results suggests that specific phobia can have severe impact on persons' lives.

Treatment for specific phobia was threefold higher in high-income countries than in lowlower middle income countries, which could be due to differences in the availability of care 
and financial resources (Saxena et al., 2007; McBain et al., 2012), the perceived need for treatment (Andrade et al., 2014), knowledge about mental healthcare (Palazzo et al., 2014), and prejudices (Clement et al., 2015; Semrau et al., 2015). Despite differences in treatment rates, associations between the level of impairment and percentages of reported treatment were comparable across the income groups, with severely impaired cases reporting most treatment. These results indicate that self-reported impairment could be an informative clinical specifier indicating need for care.

The current study had several limitations. First, diagnoses were based on structured lay interviews. However, a previous clinical reappraisal study (Haro et al., 2006) showed sufficient concordance between CIDI-based and clinical diagnoses of specific phobia. Second, all information about lifetime prevalence and AOO was reported retrospectively. This could have led to recall bias, which has been suggested to lead to underestimated lifetime prevalence rates of common mental disorders (Moffitt et al., 2010). If this bias affected reporting of specific phobia in the current study, the true lifetime prevalence and comorbidity rates could be higher. Third, the included surveys differed in terms of their response rate and sampling frames. Fifth, not all phobia types were systematically assessed (e.g. fear of choking, vomiting, contacting an illness), which could have led to underreporting. Finally, the results are based on DSM-IV criteria for specific phobia and using DSM-5 diagnoses could have led to different results. Going from DSM-IV to DSM-5, two important modifications were made to the diagnostic criteria. First, persons above 18 are no longer required to recognize that their fear/avoidance is excessive/unreasonable. Second, the fear/avoidance should at least last 6 months in all persons. Interestingly, the former modification is likely to increase prevalence, whereas the latter is likely to decrease the prevalence, possibly counteracting each other's effects. Given the fact that the core features have remained the same and the nature of the modifications, strongly differing prevalence estimations would not be expected.

Although cross-national differences were observed in the prevalence, associated impairment and treatment use, the results suggest that specific phobia is associated with considerable impairment across the world and often precedes other disorders. These findings suggest that specific phobia deserves attention of clinicians and researchers in view of its direct effects on the global burden of disease, and its role in the developmental unfolding of psychopathology.

\section{Acknowledgments}

The authors appreciate the helpful contributions to WMH of Herbert Matschinger, PhD.

Financial support

The World Health Organization World Mental Health (WMH) Survey Initiative is supported by the National Institute of Mental Health (NIMH; R01 MH070884), the John D. and Catherine T. MacArthur Foundation, the Pfizer Foundation, the US Public Health Service (R13-MH066849, R01-MH069864, and R01 DA016558), the Fogarty International Center (FIRCA R03-TW006481), the Pan American Health Organization, Eli Lilly and Company, Ortho-McNeil Pharmaceutical, GlaxoSmithKline, and Bristol-Myers Squibb. None of these funders had any role in the design, analysis, interpretation of results, or preparation of this article. A complete list of all withincountry and cross-national WMH publications can be found at http://www.hcp.med.harvard.edu/wmh/. 
Each WMH country obtained funding for its own survey. The São Paulo Megacity Mental Health Survey is supported by the State of São Paulo Research Foundation (FAPESP) Thematic Project Grant 03/00204-3. The Bulgarian Epidemiological Study of common mental disorders EPIBUL is supported by the Ministry of Health and the National Center for Public Health Protection. The Chinese World Mental Health Survey Initiative is supported by the Pfizer Foundation. The Shenzhen Mental Health Survey is supported by the Shenzhen Bureau of Health and the Shenzhen Bureau of Science, Technology, and Information. The Colombian National Study of Mental Health (NSMH) is supported by the Ministry of Social Protection. The Mental Health Study Medellín - Colombia was carried out and supported jointly by the Center for Excellence on Research in Mental Health (CES University) and the Secretary of Health of Medellín. The ESEMeD project is funded by the European Commission (Contracts QLG5-1999-01042; SANCO 2004123, and EAHC 20081308), (the Piedmont Region (Italy)), Fondo de Investigación Sanitaria, Instituto de Salud Carlos III, Spain (FIS 00/0028), Ministerio de Ciencia y Tecnología, Spain (SAF 2000-158-CE), Departament de Salut, Generalitat de Catalunya, Spain, Instituto de Salud Carlos III (CIBER CB06/02/0046, RETICS RD06/0011 REM-TAP), and other local agencies and by an unrestricted educational grant from GlaxoSmithKline. Implementation of the Iraq Mental Health Survey (IMHS) and data entry were carried out by the staff of the Iraqi MOH and MOP with direct support from the Iraqi IMHS team with funding from both the Japanese and European Funds through United Nations Development Group Iraq Trust Fund (UNDG ITF). The World Mental Health Japan (WMHJ) Survey is supported by the Grant for Research on Psychiatric and Neurological Diseases and Mental Health (H13- SHOGAI-023, H14-TOKUBETSU-026, H16KOKORO-013) from the Japan Ministry of Health, Labour and Welfare. The Lebanese National Mental Health Survey (L.E.B.A.N.O.N.) is supported by the Lebanese Ministry of Public Health, the WHO (Lebanon), National Institute of Health/Fogarty International Center (R03 TW006481- 01), Sheikh Hamdan Bin Rashid Al Maktoum Award for Medical Sciences, anonymous private donations to IDRAAC, Lebanon, and unrestricted grants from AstraZeneca, Eli Lilly, GlaxoSmithKline, Hikma Pharmaceuticals, Janssen Cilag, Lundbeck, Novartis, and Servier. The Mexican National Comorbidity Survey (MNCS) is supported by The National Institute of Psychiatry Ramon de la Fuente (INPRFMDIES 4280) and by the National Council on Science and Technology (CONACyT-G30544- H), with supplemental support from the PanAmerican Health Organization (PAHO). Dr Benjet has received funding from the (Mexican) National Council of Science and Technology (grant CB-2010-01-155221). Te Rau Hinengaro: The New Zealand Mental Health Survey (NZMHS) is supported by the New Zealand Ministry of Health, Alcohol Advisory Council, and the Health Research Council. The Nigerian Survey of Mental Health and Wellbeing (NSMHW) is supported by the WHO (Geneva), the WHO (Nigeria), and the Federal Ministry of Health, Abuja, Nigeria. The Northern Ireland Study of Mental Health was funded by the Health \& Social Care Research \& Development Division of the Public Health Agency. The Peruvian World Mental Health Study was funded by the National Institute of Health of the Ministry of Health of Peru. The Polish project Epidemiology of Mental Health and Access to Care -EZOP Poland was carried out by the Institute of Psychiatry and Neurology in Warsaw in consortium with Department of Psychiatry - Medical University in Wroclaw and National Institute of Public Health-National Institute of Hygiene in Warsaw and in partnership with Psykiatrist Institut Vinderen - Universitet, Oslo. The project was funded by the Norwegian Financial Mechanism and the European Economic Area Mechanism as well as Polish Ministry of Health. No support from pharmaceutical industry neither other commercial sources was received. The Portuguese Mental Health Study was carried out by the Department of Mental Health, Faculty of Medical Sciences, NOVA University of Lisbon, with collaboration of the Portuguese Catholic University, and was funded by Champalimaud Foundation, Gulbenkian Foundation, Foundation for Science and Technology (FCT) and Ministry of Health. The Romania WMH study projects "Policies in Mental Health Area" and "National Study regarding Mental Health and Services Use" were carried out by the National School of Public Health \& Health Services Management (former National Institute for Research \& Development in Health), with technical support of Metro Media Transilvania, the National Institute of Statistics-National Centre for Training in Statistics, SC, Cheyenne Services SRL, Statistics Netherlands and were funded by Ministry of Public Health (former Ministry of Health) with supplemental support of Eli Lilly Romania SRL. The South Africa Stress and Health Study (SASH) is supported by the US National Institute of Mental Health (R01-MH059575) and National Institute of Drug Abuse with supplemental funding from the South African Department of Health and the University of Michigan. The Psychiatric Enquiry to General Population in Southeast Spain - Murcia (PEGASUSMurcia) Project has been financed by the Regional Health Authorities of Murcia (Servicio Murciano de Salud and Consejería de Sanidad y Política Social) and Fundación para la Formación e Investigación Sanitarias (FFIS) of Murcia. The Ukraine Comorbid Mental Disorders during Periods of Social Disruption (CMDPSD) study is funded by the US National Institute of Mental Health (RO1-MH61905). The US National Comorbidity Survey Replication (NCS-R) is supported by the National Institute of Mental Health (NIMH; U01-MH60220) with supplemental support from the National Institute of Drug Abuse (NIDA), the Substance Abuse and Mental Health Services Administration (SAMHSA), the Robert Wood Johnson Foundation (RWJF; Grant 044708), and the John W. Alden Trust. Preparation of this report was supported by a VICI grant (no: 91812607) received by Peter de Jonge from the Netherlands Research Foundation (NWO-ZonMW).

In the past three years, Dr. Kessler has been a consultant for Hoffman-La Roche, Inc., Johnson \& Johnson Wellness and Prevention, and Sonofi-Aventis Groupe. Dr. Kessler has served on advisory boards for Mensante Corporation, Plus One Health Management, Lake Nona Institute, and U.S. Preventive Medicine. Dr. Kessler is a co-owner of DataStat, Inc. Dr. Demyttenaere is on the speaker bureau for Astra Zeneca, Eli Lilly, Lundbeck and Servier and has received research grants from Eli Lilly, from the foundation 'Ga voor Geluk' and from the Flemish Research Council. 


\section{Appendix}

Appendix Table 1

World Mental Health sample characteristics by World Bank Income categories ${ }^{a}$.

\begin{tabular}{|c|c|c|c|c|c|c|c|}
\hline \multirow[b]{2}{*}{ Country } & \multirow[b]{2}{*}{ Survey $^{b}$} & \multirow[b]{2}{*}{ Sample characteristics $c$} & \multirow[b]{2}{*}{ Field dates } & \multirow[b]{2}{*}{ Age range $^{d}$} & \multicolumn{2}{|c|}{$\underline{\text { Sample Size }}$} & \multirow[b]{2}{*}{$\mathbf{R e}$} \\
\hline & & & & & Part 1 & Part 2 sub-sample & \\
\hline \multicolumn{8}{|l|}{ I. Low-lower middle income } \\
\hline Colombia & NSMH & $\begin{array}{l}\text { All urban areas of the } \\
\text { country (approximately } \\
73 \% \text { of thetotal national } \\
\text { population) }\end{array}$ & 2003 & $18-65$ & 4426 & 2381 & 87. \\
\hline Iraq & IMHS & Nationally representative. & $2006-7$ & $18+$ & 4332 & 4332 & \\
\hline Nigeria & NSMHW & $\begin{array}{l}21 \text { of the } 36 \text { states in the } \\
\text { country, representing } 57 \% \\
\text { of the national population. } \\
\text { The surveys were } \\
\text { conducted in Yoruba, Igbo, } \\
\text { Hausa and Efik languages. }\end{array}$ & $2002-3$ & $18+$ & 6752 & 2143 & 79. \\
\hline Peru & EMSMP & Nationally representative. & $2004-5$ & $18-65$ & 3930 & 1801 & 90 \\
\hline PRC $^{f}$ Beijing/Shanghai & B-WMHS-WMH & $\begin{array}{l}\text { Beijing and Shanghai } \\
\text { metropolitan areas. }\end{array}$ & $2002-3$ & $18+$ & 5201 & 1628 & 74. \\
\hline $\mathrm{PRC}^{f}$ Shen Zhen & Shenzhen & $\begin{array}{l}\text { Shenzhen metropolitan } \\
\text { area. Included temporary } \\
\text { residentsas well as } \\
\text { household residents. }\end{array}$ & $2006-7$ & $18+$ & 7132 & 2475 & \\
\hline Total & & & & & 36,498 & 16,480 & \\
\hline \multicolumn{8}{|l|}{ II. Upper-middle income } \\
\hline Brazil & São Paulo Megacity & $\begin{array}{l}\text { São Paulo metropolitan } \\
\text { area. }\end{array}$ & $2005-7$ & $18+$ & 5037 & 2942 & 81. \\
\hline Bulgaria & NSHS & Nationally representative. & $2003-7$ & $18+$ & 5318 & 2233 & 72 \\
\hline Colombia (Medellin) ${ }^{g}$ & MMHHS & Medellin metropolitan area & $2011-2$ & $18-65$ & 3261 & 1673 & 97. \\
\hline Lebanon & LEBANON & Nationally representative. & $2002-3$ & $18+$ & 2857 & 1031 & 70 \\
\hline Mexico & M-NCS & $\begin{array}{l}\text { All urban areas of the } \\
\text { country (approximately } \\
75 \% \text { of the total national } \\
\text { population). }\end{array}$ & $2001-2$ & $18-65$ & 5782 & 2362 & \\
\hline Romania & RMHS & Nationally representative. & $2005-6$ & $18+$ & 2357 & 2357 & 70 \\
\hline Total & & & & & 24,612 & 12,598 & 77. \\
\hline \multicolumn{8}{|l|}{ III. High-income } \\
\hline Belgium & ESEMeD & Nationally representative. & $2001-2$ & $18+$ & 2419 & 1043 & 50 \\
\hline France & ESEMeD & Nationally representative. & $2001-2$ & $18+$ & 2894 & 1436 & 45 . \\
\hline Germany & ESEMeD & Nationally representative. & $2002-3$ & $18+$ & 3555 & 1323 & 57 \\
\hline Italy & ESEMeD & Nationally representative. & $2001-2$ & $18+$ & 4712 & 1779 & 71. \\
\hline Japan & WMHJ & Eleven metropolitan areas. & $2002-6$ & $20+$ & 4129 & 1682 & 55. \\
\hline New Zealand & NZMHS & Nationally representative. & $2003-4$ & $18+$ & 12790 & 7312 & 73. \\
\hline Northern Ireland & NISHS & Nationally representative. & $2004-7$ & $18+$ & 4340 & 1986 & 68 \\
\hline Poland & EZOP & Nationally representative. & $2010-11$ & $18-64$ & 10081 & 4000 & 50. \\
\hline Portugal & NMHS & Nationally representative. & $2008-9$ & $18+$ & 3849 & 2060 & 57. \\
\hline Spain & ESEMeD & Nationally representative. & $2001-2$ & $18+$ & 5473 & 2121 & 78. \\
\hline Spain (Murcia) & PEGASUS-Murcia & Murcia region & $2010-2$ & $18+$ & 2621 & 1459 & 67. \\
\hline The Netherlands & ESEMeD & Nationally representative. & $2002-3$ & $18+$ & 2372 & 1094 & 56 \\
\hline
\end{tabular}

Psychol Med. Author manuscript; available in PMC 2017 November 07. 


\begin{tabular}{|c|c|c|c|c|c|c|c|}
\hline \multirow[b]{2}{*}{ Country } & \multirow[b]{2}{*}{ Survey $b$} & \multirow[b]{2}{*}{ Sample characteristics $c$} & \multirow[b]{2}{*}{ Field dates } & \multirow[b]{2}{*}{ Age range $^{d}$} & \multicolumn{2}{|c|}{$\underline{\text { Sample Size }}$} & \multirow[b]{2}{*}{ Res! } \\
\hline & & & & & Part 1 & Part 2 sub-sample & \\
\hline The United States & NCS-R & Nationally representative. & $2002-3$ & $18+$ & 9282 & 5692 & 70.9 \\
\hline Total & & & & & 68,517 & 32,987 & 62.3 \\
\hline IV. Total & & & & & 124,902 & 60,345 & \\
\hline \multicolumn{5}{|c|}{ Weighted average response rate $(\%)$} & & & 69.3 \\
\hline
\end{tabular}

The World Bank (2012) Data. Accessed May 12, 2012 at: http://data.worldbank.org/country. Some of the WMH countries have moved into new income categories since the surveys were conducted. The income groupings above reflect the status of each country at the time of data collection. The current income category of each country is available at the preceding URL.

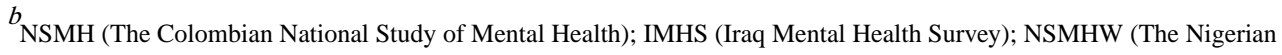
Survey of Mental Health and Wellbeing); B-WMH (The Beijing World Mental Health Survey); S-WMH (The Shanghai World Mental Health Survey); EMSMP (La Encuesta Mundial de Salud Mental en el Peru); NSHS (Bulgaria National Survey of Health and Stress); MMHHS (Medellín Mental Health Household Study); LEBANON (Lebanese Evaluation of the Burden of Ailments and Needs of the Nation); M-NCS (The Mexico National Comorbidity Survey); RMHS (Romania Mental Health Survey); ESEMeD (The European Study Of The Epidemiology Of Mental Disorders); WMHJ2002-2006 (World Mental Health Japan Survey); NZMHS (New Zealand Mental Health Survey); NISHS (Northern Ireland Study of Health and Stress); EZOP (Epidemiology of Mental Disorders and Access to Care Survey); NMHS (Portugal National Mental Health Survey); PEGASUS-Murcia (Psychiatric Enquiry to General Population in Southeast Spain-Murcia); NCS-R (The US National Comorbidity Survey Replication).

${ }^{c}$ Most WMH surveys are based on stratified multistage clustered area probability household samples in which samples of areas equivalent to counties or municipalities in the US were selected in the first stage followed by one or more subsequent stages of geographic sampling (e.g., towns within counties, blocks within towns, households within blocks) to arrive at a sample of households, in each of which a listing of household members was created and one or two people were selected from this listing to be interviewed. No substitution was allowed when the originally sampled household resident could not be interviewed. These household samples were selected from Census area data in all countries other than France (where telephone directories were used to select households) and the Netherlands (where postal registries were used to select households). Several WMH surveys (Belgium, Germany, Italy) used municipal resident registries to select respondents without listing households. The Japanese sample is the only totally un-clustered sample, with households randomly selected in each of the 11 metropolitan areas and one random respondent selected in each sample household. 16 of the 25 surveys are based on nationally representative household samples.

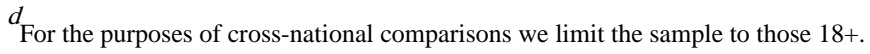

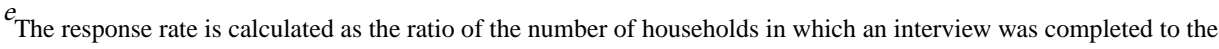
number of households originally sampled, excluding from the denominator households known not to be eligible either because of being vacant at the time of initial contact or because the residents were unable to speak the designated languages of the survey. The weighted average response rate is $69.3 \%$.

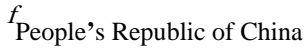

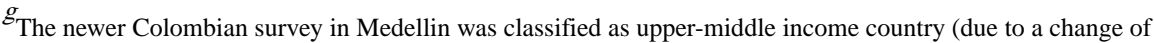
classification by The World Bank) although the original survey Colombia was classified as a low-lower middle income country. For more information, please see footnote $a$.

\section{Appendix Table 2}

Age at selected percentiles on the standardized age of onset distributions of DSM-IV specific phobia with projected lifetime risk at age 75 .

\begin{tabular}{|c|c|c|c|c|c|c|c|c|c|c|c|c|}
\hline \multirow[t]{2}{*}{ Country } & \multicolumn{8}{|c|}{ Ages at selected percentiles } & \multicolumn{2}{|c|}{$\begin{array}{l}\text { Lifetime } \\
\text { prevalence of } \\
\text { specific } \\
\text { phobia }\end{array}$} & \multicolumn{2}{|c|}{$\begin{array}{l}\text { Projected } \\
\text { risk at age } 75\end{array}$} \\
\hline & 5 & 10 & 25 & 50 & 75 & 90 & 95 & 99 & $\%$ & SE & $\%$ & $\mathbf{S E}$ \\
\hline $\begin{array}{l}\text { Low-Lower middle income } \\
\text { countries }\end{array}$ & 5 & 5 & 5 & 8 & 13 & 19 & 27 & 59 & 5.7 & 0.2 & 5.9 & 0.2 \\
\hline Colombia $^{a}$ & 5 & 5 & 5 & 8 & 12 & 20 & 39 & 61 & 12.5 & 0.8 & 13.1 & 1.1 \\
\hline Iraq & 5 & 5 & 5 & 7 & 13 & 15 & 18 & 41 & 4.2 & 0.4 & 4.3 & 0.5 \\
\hline
\end{tabular}

Psychol Med. Author manuscript; available in PMC 2017 November 07. 


\begin{tabular}{|c|c|c|c|c|c|c|c|c|c|c|c|c|}
\hline \multirow[t]{2}{*}{ Country } & \multicolumn{8}{|c|}{ Ages at selected percentiles } & \multicolumn{2}{|c|}{$\begin{array}{l}\text { Lifetime } \\
\text { prevalence of } \\
\text { specific } \\
\text { phobia }\end{array}$} & \multicolumn{2}{|c|}{$\begin{array}{l}\text { Projected } \\
\text { risk at age } 75\end{array}$} \\
\hline & 5 & 10 & 25 & 50 & 75 & 90 & 95 & 99 & $\%$ & SE & $\%$ & SE \\
\hline Nigeria & 5 & 5 & 5 & 7 & 11 & 13 & 16 & 24 & 5.9 & 0.5 & 6.0 & 0.5 \\
\hline Peru $^{a}$ & 5 & 5 & 7 & 10 & 13 & 20 & 27 & 36 & 6.6 & 0.4 & 6.8 & 0.4 \\
\hline PRC China & 5 & 5 & 5 & 13 & 17 & 36 & 41 & 59 & 2.6 & 0.3 & 2.8 & 0.4 \\
\hline PRC Shen Zhen & 5 & 5 & 6 & 8 & 13 & 19 & 26 & 33 & 4.0 & 0.3 & 4.1 & 0.3 \\
\hline Upper-middle income countries & 5 & 5 & 5 & 9 & 13 & 29 & 50 & 68 & 8.0 & 0.2 & 8.6 & 0.3 \\
\hline Brazil & 5 & 5 & 5 & 8 & 13 & 26 & 51 & 56 & 12.5 & 0.6 & 13.5 & 0.7 \\
\hline Bulgaria & 5 & 5 & 5 & 11 & 16 & 33 & 51 & 70 & 5.8 & 0.3 & 6.1 & 0.4 \\
\hline Colombia (Medellin) ${ }^{a}$ & 5 & 5 & 5 & 7 & 11 & 19 & 30 & 46 & 10.2 & 0.8 & 10.5 & 0.9 \\
\hline Lebanon & 5 & 5 & 5 & 11 & 13 & 29 & 48 & 68 & 7.0 & 0.5 & 7.9 & 0.7 \\
\hline Mexico $^{a}$ & 5 & 5 & 7 & 9 & 16 & 31 & 50 & 63 & 7.0 & 0.5 & 7.7 & 0.6 \\
\hline Romania & 5 & 5 & 5 & 9 & 18 & 48 & 53 & 58 & 3.8 & 0.5 & 4.3 & 0.5 \\
\hline High income countries & 5 & 5 & 5 & 8 & 13 & 29 & 41 & 63 & 8.1 & 0.1 & 8.8 & 0.2 \\
\hline Belgium & 5 & 5 & 5 & 9 & 18 & 51 & 65 & 72 & 6.8 & 1.0 & 8.0 & 1.4 \\
\hline France & 5 & 5 & 5 & 8 & 13 & 29 & 41 & 45 & 10.7 & 0.6 & 11.5 & 0.8 \\
\hline Germany & 5 & 5 & 5 & 8 & 14 & 26 & 41 & 63 & 9.9 & 0.7 & 10.7 & 0.8 \\
\hline Italy & 5 & 5 & 5 & 8 & 14 & 28 & 44 & 61 & 5.4 & 0.5 & 5.7 & 0.5 \\
\hline Japan & 5 & 5 & 5 & 8 & 13 & 26 & 33 & 56 & 3.4 & 0.3 & 3.7 & 0.3 \\
\hline New Zealand & 5 & 5 & 5 & 8 & 13 & 26 & 39 & 56 & 10.9 & 0.4 & 11.9 & 0.4 \\
\hline Northern Ireland & 5 & 5 & 5 & 8 & 13 & 22 & 31 & 63 & 9.7 & 0.6 & 10.3 & 0.6 \\
\hline Poland $b$ & 5 & 5 & 5 & 8 & 14 & 21 & 33 & 56 & 3.4 & 0.2 & 3.5 & 0.2 \\
\hline Portugal & 5 & 5 & 5 & 8 & 13 & 31 & 47 & 59 & 10.6 & 0.6 & 11.5 & 0.7 \\
\hline Spain & 5 & 5 & 5 & 7 & 16 & 43 & 56 & 66 & 4.8 & 0.4 & 5.5 & 0.5 \\
\hline Spain (Murcia) & 5 & 5 & 5 & 9 & 22 & 48 & 55 & 68 & 5.4 & 0.5 & 6.6 & 0.8 \\
\hline The Netherlands & 5 & 5 & 6 & 8 & 13 & 26 & 36 & 59 & 7.6 & 0.7 & 8.1 & 0.7 \\
\hline The United States & 5 & 5 & 5 & 7 & 12 & 23 & 41 & 64 & 12.5 & 0.4 & 13.7 & 0.5 \\
\hline All countries combined & 5 & 5 & 5 & 8 & 13 & 27 & 42 & 63 & 7.4 & 0.1 & 8.1 & 0.1 \\
\hline
\end{tabular}

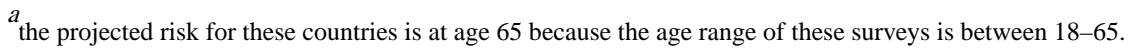

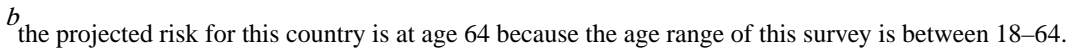

\section{Appendix Table 3}

Bivariate associations between socio-demographics correlates and DSM-IV specific phobia (low-lower middle income countries).

\begin{tabular}{|c|c|c|c|c|c|c|c|c|}
\hline \multirow[t]{2}{*}{ Correlates } & \multicolumn{2}{|c|}{ 30-day Specific Phobia ${ }^{a}$} & \multicolumn{2}{|c|}{ Lifetime Specific Phobia $^{b}$} & \multicolumn{2}{|c|}{$\begin{array}{l}\text { 12-month Specific } \\
\text { Phobia among } \\
\text { lifetime cases }^{c}\end{array}$} & \multicolumn{2}{|c|}{$\begin{array}{l}\text { 30-day Specific } \\
\text { Phobia among 12- } \\
\text { month cases }{ }^{c}\end{array}$} \\
\hline & OR & $(95 \% \mathrm{CI})$ & OR & $(95 \% \mathrm{CI})$ & OR & $(95 \% \mathrm{CI})$ & OR & $(95 \% \mathrm{CI})$ \\
\hline \multicolumn{9}{|l|}{ Age-cohort } \\
\hline $18-29$ & $1.5^{*}$ & $(1.0-2.1)$ & $1.6^{*}$ & $(1.3-2.0)$ & - & - & - & - \\
\hline $30-44$ & 1.2 & $(0.1 .7)$ & 1.2 & $(1.0-1.5)$ & - & - & - & - \\
\hline $45-59$ & 1.2 & $(0.8-1.7)$ & 1.2 & $(0.9-1.5)$ & - & - & - & - \\
\hline
\end{tabular}

Psychol Med. Author manuscript; available in PMC 2017 November 07. 


\begin{tabular}{|c|c|c|c|c|c|c|c|c|}
\hline \multirow[t]{2}{*}{ Correlates } & \multicolumn{2}{|c|}{ 30-day Specific Phobia ${ }^{a}$} & \multicolumn{2}{|c|}{ Lifetime Specific Phobia ${ }^{b}$} & \multicolumn{2}{|c|}{$\begin{array}{l}\text { 12-month Specific } \\
\text { Phobia among } \\
\text { lifetime cases }^{c}\end{array}$} & \multicolumn{2}{|c|}{$\begin{array}{l}\text { 30-day Specific } \\
\text { Phobia among 12- } \\
\text { month cases }\end{array}$} \\
\hline & OR & $(95 \% \mathrm{CI})$ & OR & $(95 \% \mathrm{CI})$ & OR & $(95 \% \mathrm{CI})$ & OR & $(95 \%$ CI $)$ \\
\hline $60+$ & 1.0 & & 1.0 & & - & - & - & - \\
\hline Age-cohort difference $^{d}$ & \multicolumn{2}{|c|}{$\chi^{2}{ }_{3}=8.7^{*} . \mathrm{P}=0.03$} & \multicolumn{2}{|c|}{$\chi^{2}{ }_{3}=31.7^{*} . \mathrm{P}<.001$} & & & & \\
\hline \multicolumn{9}{|l|}{ Age of onset } \\
\hline Early & - & - & - & - & 1.1 & $(0.7-1.7)$ & 0.8 & $(0.5-1.4)$ \\
\hline Early-average & - & - & - & - & 1.0 & $(0.6-1.5)$ & 0.8 & $(0.4-1.3)$ \\
\hline Late-average & - & - & - & - & 1.0 & $(0.7-1.5)$ & $0.6^{*}$ & $(0.4-1.0)$ \\
\hline Late & - & - & - & - & 1.0 & & 1.0 & \\
\hline Age of onset difference ${ }^{d}$ & & & & & $\chi^{2}{ }_{3}=$ & .3. $\mathrm{P}=0.96$ & $\chi^{2}{ }_{3}=$ & 4.9. $\mathrm{P}=0.183$ \\
\hline \multirow[t]{2}{*}{ Time since onset (Continuous) } & - & - & - & - & 1.00 & $(0.99-1.01)$ & 1.00 & $(0.99-1.01)$ \\
\hline & & & & & \multicolumn{2}{|c|}{$\chi^{2}{ }_{1}=0.0 . \mathrm{P}=0.84$} & \multicolumn{2}{|c|}{$\chi_{1}^{2}=0.1 . P=0.79$} \\
\hline \multicolumn{9}{|l|}{ Gender } \\
\hline Female & $2.0^{*}$ & $(1.6-2.5)$ & $1.5^{*}$ & $(1.3-1.8)$ & $1.5^{*}$ & $(1.1-2.1)$ & 1.2 & $(0.9-1.7)$ \\
\hline Male & 1.0 & & 1.0 & & 1.0 & & 1.0 & \\
\hline Gender difference $^{d}$ & \multicolumn{2}{|c|}{$\chi^{2}{ }_{1}=35.8^{*} . \mathrm{P}<.001$} & \multicolumn{2}{|c|}{$\chi^{2}{ }_{1}=7.2^{*} . \mathrm{P}<.001$} & \multicolumn{2}{|c|}{$\chi^{2}{ }_{1}=7.5^{*} \cdot \mathrm{P}=0.006$} & \multicolumn{2}{|c|}{$\chi^{2}{ }_{1}=1.7 . P=0.190$} \\
\hline \multicolumn{9}{|l|}{ Employment status } \\
\hline Student & 1.1 & $(0.8-1.7)$ & 1.1 & $(0.9-1.4)$ & 0.8 & $(0.5-1.4)$ & 1.3 & $(0.7-2.2)$ \\
\hline Homemaker & $1.6^{*}$ & $(1.3-2.1)$ & $1.4^{*}$ & $(1.2-1.7)$ & 1.3 & $(0.8-2.0)$ & 1.3 & $(0.8-2.0)$ \\
\hline Retired & 1.4 & $(0.8-2.4)$ & $1.6^{*}$ & $(1.1-2.2)$ & 1.0 & $(0.4-2.4)$ & 0.6 & $(0.2-1.4)$ \\
\hline Other & $1.5^{*}$ & $(1.2-2.0)$ & $1.3^{*}$ & $(1.1-1.6)$ & $1.8^{*}$ & $(1.1-3.1)$ & 1.1 & $(0.7-1.7)$ \\
\hline Employed & 1.0 & & 1.0 & & 1.0 & & 1.0 & \\
\hline Employment status difference ${ }^{d}$ & \multicolumn{2}{|c|}{$\chi^{2}{ }_{4}=20.4^{*} \cdot \mathrm{P}<.001$} & \multicolumn{2}{|c|}{$\chi^{2}{ }_{4}=18.6^{*} . \mathrm{P}<.001$} & \multicolumn{2}{|c|}{$\chi^{2}{ }_{4}=6.1 . P=0.19$} & \multicolumn{2}{|c|}{$\chi^{2}{ }_{4}=3.3 . P=0.52$} \\
\hline \multicolumn{9}{|l|}{ Marital status } \\
\hline Never married & 1.2 & $(1.0-1.6)$ & 1.2 & $(1.0-1.4)$ & 1.0 & $(0.7-1.4)$ & 1.1 & $(0.8-1.5)$ \\
\hline Divorced/separated/widowed & 1.1 & $(0.7-1.5)$ & 1.1 & $(0.9-1.3)$ & 1.1 & $(0.6-2.0)$ & 0.9 & $(0.5-1.5)$ \\
\hline Currently married & 1.0 & & 1.0 & & 1.0 & & 10 & \\
\hline Marital status difference $^{d}$ & \multicolumn{2}{|c|}{$\chi_{2}^{2}=3.1 . \mathrm{P}=0.22$} & \multicolumn{2}{|c|}{$\chi_{2}^{2}=4.1 . P=0.13$} & $\chi_{2}^{2}=$ & .2. $P=0.93$ & $\chi_{2}^{2}=$ & .4. $P=0.81$ \\
\hline Education level & & & & & & & & \\
\hline No education & 1.6 & $(1.0-2.6)$ & $1.6^{*}$ & $(1.1-2.3)$ & 1.3 & $(0.6-2.4)$ & 1.1 & $(0.5-2.3)$ \\
\hline Some primary & $1.7^{*}$ & $(1.0-2.8)$ & $1.9^{*}$ & $(1.4-2.7)$ & 0.7 & $(0.3-1.4)$ & 1.0 & $(0.4-2.1)$ \\
\hline Finished primary & $1.8^{*}$ & $(1.2-2.9)$ & $1.9^{*}$ & $(1.4-2.6)$ & 0.9 & $(0.5-1.7)$ & 0.9 & $(0.4-1.9)$ \\
\hline Some secondary & 1.3 & $(0.9-2.0)$ & $1.7^{*}$ & $(1.2-2.2)$ & 1.0 & $(0.6-1.6)$ & 0.6 & $(0.3-1.2)$ \\
\hline Finished secondary & 1.4 & $(0.9-2.1)$ & $1.7^{*}$ & $(1.3-2.2)$ & 0.7 & $(0.4-1.2)$ & 0.9 & $(0.5-1.6)$ \\
\hline Some college & 1.2 & $(0.8-2.0)$ & $1.8^{*}$ & $(1.4-2.4)$ & 0.7 & $(0.4-1.2)$ & 0.6 & $(0.3-1.1)$ \\
\hline Finished college & 1.0 & & 1.0 & & 1.0 & & 1.0 & \\
\hline Education level difference $^{d}$ & $\chi_{3}^{2}=c$ & $\mathrm{P}=0.17$ & $\chi_{3}^{2}=$ & $\mathrm{P}=.003$ & $\chi_{3}^{2}=$ & 5.6. $P=0.47$ & $\chi^{2}{ }_{3}=$ & 7.1. $P=0.31$ \\
\hline Household income & & & & & & & & \\
\hline Low & $1.4^{*}$ & $(1.1-1.9)$ & 1.2 & $(1.0-1.5)$ & 1.1 & $(0.8-1.7)$ & 1.4 & $(0.9-2.1)$ \\
\hline Low-average & 1.2 & $(0.9-1.6)$ & 1.1 & $(0.9-1.3)$ & 1.4 & $(0.9-2.2)$ & 1.1 & $(0.7-1.8)$ \\
\hline High-average & 0.9 & $(0.6-1.2)$ & 1.0 & $(0.8-1.2)$ & 0.8 & $(0.5-1.2)$ & 0.9 & $(0.6-1.5)$ \\
\hline High & 1.0 & & 1.0 & & 1.0 & & 1.0 & \\
\hline
\end{tabular}

Psychol Med. Author manuscript; available in PMC 2017 November 07. 


\begin{tabular}{|c|c|c|c|c|}
\hline \multirow[t]{2}{*}{ Correlates } & 30-day Specific Phobia ${ }^{a}$ & Lifetime Specific Phobia $b$ & $\begin{array}{l}\text { 12-month Specific } \\
\text { Phobia among } \\
\text { lifetime cases }^{c}\end{array}$ & $\begin{array}{l}\text { 30-day Specific } \\
\text { Phobia among 12- } \\
\text { month cases } c\end{array}$ \\
\hline & $(95 \% \mathrm{CI})$ & $(95 \% \mathrm{CI})$ & $(95 \% \mathrm{CI})$ & $(95 \% \mathrm{CI})$ \\
\hline Household income difference ${ }^{d}$ & $\chi^{2}{ }_{3}=15.8^{*} \cdot \mathrm{P}=.001$ & $\chi^{2}{ }_{3}=6.7 . \mathrm{P}=0.08$ & $\chi^{2}{ }_{3}=5.6 . \mathrm{P}=0.14$ & $\chi^{2}{ }_{3}=4.3 . P=0.23$ \\
\hline $\mathrm{N}^{e}$ & 31773 & 1158886 & 1748 & 1254 \\
\hline \multicolumn{5}{|c|}{ * Significant at the .05 level. 2 sided test. } \\
\hline \multicolumn{5}{|c|}{ a These estimates are based on logistic regression models adjusted for age. gender and low-lower middle income countries. } \\
\hline \multicolumn{5}{|c|}{$\begin{array}{l}b \text { These estimates are based on survival models adjusted for age-cohorts. gender. person-years and low-lower middle income } \\
\text { countries. }\end{array}$} \\
\hline \multicolumn{5}{|c|}{$\begin{array}{l}c \text { These estimates are based on logistic regression models adjusted for time since specific phobia onset. age of specific } \\
\text { phobia onset. gender and low-lower middle income countries. } \\
{ }^{d} \text { Chi square test of significant differences between blocks of sociodemographic variables. }\end{array}$} \\
\hline
\end{tabular}

\section{Appendix Table 4}

Bivariate associations between socio-demographics correlates and DSM-IV specific phobia (upper-middle income countries).

\begin{tabular}{|c|c|c|c|c|c|c|c|c|}
\hline \multirow[t]{2}{*}{ Correlates } & \multicolumn{2}{|c|}{ 30-day Specific Phobia ${ }^{a}$} & \multicolumn{2}{|c|}{ Lifetime Specific Phobia $b$} & \multicolumn{2}{|c|}{$\begin{array}{l}\text { 12-month Specific } \\
\text { Phobia among } \\
\text { lifetime cases }^{c}\end{array}$} & \multicolumn{2}{|c|}{$\begin{array}{l}\text { 30-day Specific } \\
\text { Phobia among 12- } \\
\text { month cases }\end{array}$} \\
\hline & OR & $(95 \% \mathrm{CI})$ & OR & $(95 \% \mathrm{CI})$ & OR & $(95 \% \mathrm{CI})$ & OR & $(95 \% \mathrm{CI})$ \\
\hline \multicolumn{9}{|l|}{ Age-cohort } \\
\hline $18-29$ & 1.1 & $(0.9-1.3)$ & $1.3^{*}$ & $(1.1-1.6)$ & - & - & - & - \\
\hline $30-44$ & $1.3^{*}$ & $(1.0-1.5)$ & $1.4^{*}$ & $(1.1-1.6)$ & - & - & - & - \\
\hline $45-59$ & $1.3^{*}$ & $(1.0-1.6)$ & $1.4^{*}$ & $(1.2-1.7)$ & - & - & - & - \\
\hline $60+$ & \multicolumn{2}{|l|}{1.0} & \multicolumn{4}{|l|}{1.0} & & \\
\hline Age-cohort difference ${ }^{d}$ & \multicolumn{2}{|c|}{$\chi^{2}{ }_{3}=7.8^{*} \cdot \mathrm{P}=0.05$} & \multicolumn{4}{|c|}{$\chi^{2}{ }_{3}=16.6^{*} \cdot \mathrm{P}=0.001$} & & \\
\hline \multicolumn{9}{|l|}{ Age of onset } \\
\hline Early & - & - & - & - & $1.7^{*}$ & $(1.1-2.6)$ & 1.1 & $(0.7-1.7)$ \\
\hline Early-average & - & - & - & - & 1.2 & $(0.8-1.9)$ & 0.9 & $(0.6-1.5)$ \\
\hline Late-average & - & - & - & - & 1.0 & $(0.7-1.5)$ & 0.9 & $(0.6-1.4)$ \\
\hline Late & - & - & - & - & 1.0 & & 1.0 & \\
\hline Age of onset difference ${ }^{d}$ & & & & & $\chi^{2}{ }_{3}=$ & 1. $p=0.07$ & $\chi^{2}{ }_{3}=0$ & $\mathrm{P}=0.83$. \\
\hline \multirow[t]{2}{*}{ Time since onset (Continuous) } & - & - & - & - & 1.00 & $(0.99-1.01)$ & $1.01^{*}$ & $(1.00-1.02)$ \\
\hline & & & & & \multicolumn{2}{|c|}{$\chi^{2}{ }_{1}=0.5 . \mathrm{P}=0.47$} & \multicolumn{2}{|c|}{$\chi^{2}=5.5^{*} \cdot \mathrm{P}=0.02$} \\
\hline \multicolumn{9}{|l|}{ Gender } \\
\hline Female & $3.1^{*}$ & $(2.6-3.7)$ & $2.3^{*}$ & $(2.0-2.6)$ & $1.8^{*}$ & $(1.3-2.5)$ & $1.9^{*}$ & $(1.4-2.5)$ \\
\hline Male & 1.0 & & 1.0 & & 1.0 & & 1.0 & \\
\hline Gender difference $^{d}$ & \multicolumn{2}{|c|}{$\chi^{2}{ }_{1}=175.5^{*} . \mathrm{P}<.001$} & \multicolumn{2}{|c|}{$\chi^{2}{ }_{1}=161.0^{*} . \mathrm{P}<.001$} & \multicolumn{2}{|c|}{$\chi^{2}{ }_{1}=13.6^{*} . P<.001$} & \multicolumn{2}{|c|}{$\chi^{2}{ }_{1}=16.5^{*} \cdot \mathrm{P}<.001$} \\
\hline \multicolumn{9}{|l|}{ Employment status } \\
\hline Student & 0.8 & $(0.5-1.2)$ & 1.2 & $(0.9-1.6)$ & 1.9 & $(0.9-4.1)$ & $0.5^{*}$ & $(0.2-0.9)$ \\
\hline Homemaker & 1.2 & $(1.0-1.4)$ & 1.2 & $(1.0-1.3)$ & 1.2 & $(0.7-1.8)$ & 1.0 & $(0.7-1.6)$ \\
\hline Retired & 0.9 & $(0.7-1.2)$ & 1.2 & $(0.9-1.5)$ & 1.3 & $(0.7-2.4)$ & 0.7 & $(0.4-1.3)$ \\
\hline
\end{tabular}




\begin{tabular}{|c|c|c|c|c|c|c|c|c|}
\hline \multirow[t]{2}{*}{ Correlates } & \multicolumn{2}{|c|}{ 30-day Specific Phobia ${ }^{a}$} & \multicolumn{2}{|c|}{ Lifetime Specific Phobia $b$} & \multicolumn{2}{|c|}{$\begin{array}{l}\text { 12-month Specific } \\
\text { Phobia among } \\
\text { lifetime cases }\end{array}$} & \multicolumn{2}{|c|}{$\begin{array}{l}\text { 30-day Specific } \\
\text { Phobia among 12- } \\
\text { month cases }{ }^{c}\end{array}$} \\
\hline & OR & $(95 \% \mathrm{CI})$ & OR & $(95 \% \mathrm{CI})$ & OR & $(95 \% \mathrm{CI})$ & OR & $(95 \% \mathrm{CI})$ \\
\hline Other & 1.2 & $(1.0-1.6)$ & $1.3^{*}$ & $(1.1-1.5)$ & 1.0 & $(0.6-1.8)$ & 1.1 & $(0.7-1.7)$ \\
\hline Employed & \multicolumn{2}{|l|}{1.0} & \multicolumn{2}{|l|}{1.0} & \multicolumn{2}{|l|}{1.0} & \multicolumn{2}{|l|}{1.0} \\
\hline Employment status difference $^{d}$ & \multicolumn{2}{|c|}{$\chi^{2}{ }_{4}=9.5 . \mathrm{P}=0.05$} & \multicolumn{2}{|c|}{$\chi^{2}{ }_{4}=9.3 . P=0.06$} & \multicolumn{2}{|c|}{$\chi^{2}{ }_{4}=4.2 . \mathrm{P}=0.38$} & \multicolumn{2}{|c|}{$\chi^{2}{ }_{4}=7.4 . \mathrm{P}=0.12$} \\
\hline \multicolumn{9}{|l|}{ Marital status } \\
\hline Never married & 0.9 & $(0.7-1.1)$ & 0.9 & $(0.8-1.1)$ & 1.1 & $(0.8-1.6)$ & 1.0 & $(0.7-1.5)$ \\
\hline Divorced/separated/widowed & 0.9 & $(0.7-1.1)$ & 1.1 & $(0.9-1.3)$ & 0.9 & $(0.6-1.5)$ & 0.7 & $(0.5-1.1)$ \\
\hline Currently married & 1.0 & & 1.0 & & 1.0 & & 1.0 & \\
\hline Marital status difference ${ }^{d}$ & \multicolumn{2}{|c|}{$\chi_{2}^{2}=2.2 . \mathrm{P}=0.34$} & \multicolumn{2}{|c|}{$\chi^{2}{ }_{2}=1.4 . P=0.49$} & \multicolumn{2}{|c|}{$\chi^{2}{ }_{2}=0.4 . \mathrm{P}=0.81$} & \multicolumn{2}{|c|}{$\chi_{2}^{2}=2.4 . \mathrm{P}=0.30$} \\
\hline \multicolumn{9}{|l|}{ Education level } \\
\hline No education & 1.4 & $(0.9-2.1)$ & 1.2 & $(0.9-1.7)$ & 1.0 & $(0.4-2.5)$ & 3.3 & $(1.0-11.1)$ \\
\hline Some primary & $1.8^{*}$ & $(1.4-2.4)$ & $1.7^{*}$ & $(1.4-2.0)$ & 1.4 & $(0.7-2.7)$ & 1.1 & $(0.6-1.8)$ \\
\hline Finished primary & $1.4^{*}$ & $(1.0-1.9)$ & $1.3^{*}$ & $(1.1-1.6)$ & 1.0 & $(0.5-2.1)$ & 1.1 & $(0.6-1.9)$ \\
\hline Some secondary & $1.5^{*}$ & $(1.2-2.0)$ & $1.5^{*}$ & $(1.2-1.8)$ & 1.3 & $(0.7-2.3)$ & 1.1 & $(0.6-1.8)$ \\
\hline Finished secondary & 1.2 & $(0.9-1.6)$ & 1.1 & $(0.9-1.3)$ & 1.5 & $(0.8-2.7)$ & 1.2 & $(0.7-2.0)$ \\
\hline Some college & 1.4 & $(1.0-2.0)$ & $1.4^{*}$ & $(1.1-1.8)$ & 1.1 & $(0.6-2.2)$ & 1.1 & $(0.6-1.9)$ \\
\hline Finished college & 1.0 & & 1.0 & & 1.0 & & 1.0 & \\
\hline Education level difference $^{d}$ & \multicolumn{2}{|c|}{$\chi^{2}{ }_{3}=31.0^{*} . \mathrm{P}<.001$} & \multicolumn{2}{|c|}{$\chi^{2}{ }_{3}=49.1^{*} \cdot \mathrm{P}<.001$} & \multicolumn{2}{|c|}{$\chi_{3}^{2}=3.2 . \mathrm{P}=0.79$} & \multicolumn{2}{|c|}{$\chi^{2}{ }_{3}=4.2 . \mathrm{P}=0.65$} \\
\hline \multicolumn{9}{|l|}{ Household income } \\
\hline Low & 1.2 & $(1.0-1.5)$ & 1.1 & $(0.9-1.3)$ & 0.9 & $(0.6-1.3)$ & 1.5 & $(1.0-2.4)$ \\
\hline Low-average & 1.2 & $(0.9-1.5)$ & 1.2 & $(1.0-1.4)$ & 1.3 & $(0.8-2.0)$ & 0.9 & $(0.6-1.4)$ \\
\hline High-average & 1.2 & $(1.0-1.5)$ & 1.1 & $(0.9-1.3)$ & 1.3 & $(0.9-2.0)$ & 1.3 & $(0.8-2.0)$ \\
\hline High & \multicolumn{2}{|l|}{1.0} & \multicolumn{2}{|l|}{1.0} & \multicolumn{2}{|l|}{1.0} & \multicolumn{2}{|l|}{1.0} \\
\hline Household income difference ${ }^{d}$ & \multicolumn{2}{|c|}{$\chi_{3}^{2}=3.7 . P=0.30$} & \multicolumn{2}{|c|}{$\chi_{3}^{2}=2.3 . P=0.52$} & \multicolumn{2}{|c|}{$\chi_{P}^{2}{ }_{3}=5.7 . P=0.13$} & \multicolumn{2}{|c|}{$\chi^{2}{ }_{3}=5.9 . \mathrm{P}=0.12$} \\
\hline $\mathrm{N}^{e}$ & 24612 & & 998615 & & 2028 & & 1630 & \\
\hline
\end{tabular}

"Significant at the .05 level. 2 sided test.

${ }^{a}$ These estimates are based on logistic regression models adjusted for age. gender and upper-middle income countries.

$b_{\text {These estimates are based on survival models adjusted for age-cohorts. gender. person-years and upper-middle income }}$ countries.

${ }^{c}$ These estimates are based on logistic regression models adjusted for time since specific phobia onset. age of specific phobia onset. gender and upper-middle income countries.

${ }^{d}$ Chi square test of significant differences between blocks of sociodemographic variables.

$e_{\text {Denominator N: }}$ 24.612= total sample; $998.615=$ number of person-years in the survival models; $2.028=$ number of lifetime cases of specific phobia; $1.630=$ number of 12 -month cases of specific phobia. 


\section{Appendix Table 5}

Bivariate associations between socio-demographics correlates and DSM-IV specific phobia (high income countries).

\begin{tabular}{|c|c|c|c|c|c|c|c|c|}
\hline \multirow[t]{2}{*}{ Correlates } & \multicolumn{2}{|c|}{ 30-day Specific Phobia ${ }^{a}$} & \multicolumn{2}{|c|}{ Lifetime Specific Phobia ${ }^{b}$} & \multicolumn{2}{|c|}{$\begin{array}{l}\text { 12-month Specific } \\
\text { Phobia among } \\
\text { lifetime cases }^{c}\end{array}$} & \multicolumn{2}{|c|}{$\begin{array}{l}\text { 30-day Specific } \\
\text { Phobia among 12- } \\
\text { month cases }^{c}\end{array}$} \\
\hline & OR & $(95 \% \mathrm{CI})$ & OR & $(95 \% \mathrm{CI})$ & OR & $(95 \% \mathrm{CI})$ & OR & $(95 \% \mathrm{CI})$ \\
\hline \multicolumn{9}{|l|}{ Age-cohort } \\
\hline $18-29$ & $1.5^{*}$ & $(1.4-1.8)$ & $2.0^{*}$ & $(1.8-2.2)$ & - & - & - & - \\
\hline $30-44$ & $1.5^{*}$ & $(1.3-1.7)$ & $1.7^{*}$ & $(1.5-1.8)$ & - & - & - & - \\
\hline $45-59$ & $1.5^{*}$ & $(1.3-1.7)$ & $1.6^{*}$ & $(1.4-1.7)$ & - & - & - & - \\
\hline $60+$ & \multicolumn{2}{|l|}{1.0} & \multicolumn{2}{|l|}{1.0} & & & & \\
\hline Age-cohort difference ${ }^{d}$ & \multicolumn{2}{|c|}{$\chi_{3}^{2}=50.0 * . P<.001$} & \multicolumn{2}{|c|}{$\chi^{2}{ }_{3}=182.3^{*} . \mathrm{P}<.001$} & & & & \\
\hline \multicolumn{9}{|l|}{ Age of onset } \\
\hline Early & - & - & - & - & $1.5^{*}$ & $(1.2-1.9)$ & 0.9 & $(0.7-1.2)$ \\
\hline Early-average & - & - & - & - & 1.1 & $(0.9-1.4)$ & 0.8 & $(0.6-1.1)$ \\
\hline Late-average & - & - & - & - & 1.1 & $(0.9-1.4)$ & 0.8 & $(0.6-1.0)$ \\
\hline Late & - & - & - & - & 1.0 & & 1.0 & \\
\hline Age of onset difference ${ }^{d}$ & & & & & $\chi^{2}{ }_{3}=1$ & $4^{*} \cdot \mathrm{P}=0.001$ & $\chi^{2}{ }_{3}=$ & 5. $\mathrm{P}=0.32$ \\
\hline \multirow[t]{2}{*}{ Time since onset (Continuous) } & - & - & - & - & $0.99^{*}$ & $(0.99-1.00)$ & $1.01^{*}$ & $(1.01-1.02)$ \\
\hline & & & & & \multicolumn{2}{|c|}{$\chi^{2}{ }_{1}=7.4^{*} \cdot \mathrm{P}=0.007$} & \multicolumn{2}{|c|}{$\chi^{2}{ }_{1}=20.2^{*} . \mathrm{P}<.001$} \\
\hline \multicolumn{9}{|l|}{ Gender } \\
\hline Female & $2.8^{*}$ & $(2.6-3.1)$ & $2.2^{*}$ & $(2.0-2.3)$ & $1.9^{*}$ & $(1.7-2.3)$ & $1.2^{*}$ & $(1.0-1.5)$ \\
\hline Male & 1.0 & & 1.0 & & 1.0 & & 1.0 & \\
\hline Gender difference $^{d}$ & \multicolumn{2}{|c|}{$\chi^{2}{ }_{1}=453.6^{*} . P<.001$} & \multicolumn{2}{|c|}{$\chi^{2}{ }_{1}=508.7^{*} \cdot \mathrm{P}<.001$} & \multicolumn{2}{|c|}{$\chi^{2}{ }_{1}=77.3^{*} . \mathrm{P}<.001$} & \multicolumn{2}{|c|}{$\chi^{2}{ }_{1}=4.7^{*} \cdot \mathrm{P}=0.03$} \\
\hline \multicolumn{9}{|l|}{ Employment status } \\
\hline Student & 1.0 & $(0.8-1.3)$ & 1.0 & $(0.9-1.2)$ & 1.5 & $(0.9-2.4)$ & 1.0 & $(0.6-1.4)$ \\
\hline Homemaker & $1.3^{*}$ & $(1.1-1.4)$ & 1.1 & $(1.0-1.2)$ & 1.2 & $(1.0-1.5)$ & $1.4^{*}$ & $(1.1-1.8)$ \\
\hline Retired & 1.1 & $(0.9-1.3)$ & 1.1 & $(0.9-1.2)$ & $1.3^{*}$ & $(1.1-1.7)$ & 1.1 & $(0.8-1.5)$ \\
\hline Other & $2.0^{*}$ & $(1.7-2.2)$ & $1.5^{*}$ & $(1.3-1.7)$ & $1.5^{*}$ & $(1.2-1.9)$ & $1.5^{*}$ & $(1.2-2.0)$ \\
\hline Employed & 1.0 & & 1.0 & & 1.0 & & 1.0 & \\
\hline Employment status difference ${ }^{d}$ & \multicolumn{2}{|c|}{$\chi^{2}{ }_{4}=91.5^{*} . \mathrm{P}<.001$} & \multicolumn{2}{|c|}{$\chi^{2}{ }_{4}=64.4^{*} . \mathrm{P}<.001$} & \multicolumn{2}{|c|}{$\chi^{2}{ }_{4}=22.5^{*} . \mathrm{P}<.001$} & \multicolumn{2}{|c|}{$\begin{array}{l}\chi_{4}^{2}=15.1^{*} . \mathrm{P}= \\
0.005\end{array}$} \\
\hline \multicolumn{9}{|l|}{ Marital status } \\
\hline Never married & 0.9 & $(0.8-1.0)$ & 1.0 & $(0.9-1.1)$ & 1.1 & $(0.9-1.3)$ & 1.0 & $(0.8-1.2)$ \\
\hline Divorced/separated/widowed & $1.4^{*}$ & $(1.2-1.6)$ & $1.3^{*}$ & $(1.2-1.4)$ & 1.1 & $(0.9-1.4)$ & $1.3^{*}$ & $(1.0-1.6)$ \\
\hline Currently married & 1.0 & & 1.0 & & 1.0 & & 1.0 & \\
\hline Marital status difference $^{d}$ & \multicolumn{2}{|c|}{$\chi_{2}^{2}=30.3^{*} . \mathrm{P}<.001$} & $\chi_{2}^{2}=2$ & $* . \mathrm{P}<.001$ & $\chi_{2}^{2}=1$ & 5. $P=0.47$ & $\chi_{2}^{2}=$ & 6. $P=0.06$ \\
\hline Education level & & & & & & & & \\
\hline No education & $1.9^{*}$ & $(1.1-3.4)$ & 1.6 & $(1.0-2.6)$ & 2.2 & $(0.8-5.6)$ & 1.2 & $(0.4-3.8)$ \\
\hline Some primary & $2.4^{*}$ & $(2.0-2.9)$ & $1.7^{*}$ & $(1.4-2.0)$ & $2.7^{*}$ & $(1.9-3.9)$ & $1.7^{*}$ & $(1.1-2.6)$ \\
\hline Finished primary & $2.2^{*}$ & $(1.8-2.8)$ & $1.6^{*}$ & $(1.3-1.9)$ & $2.2^{*}$ & $(1.5-3.2)$ & $1.6^{*}$ & $(1.1-2.3)$ \\
\hline Some secondary & $1.8^{*}$ & $(1.5-2.1)$ & $1.5^{*}$ & $(1.3-1.6)$ & $1.4^{*}$ & $(1.1-1.8)$ & $1.4^{*}$ & $(1.1-1.9)$ \\
\hline
\end{tabular}

Psychol Med. Author manuscript; available in PMC 2017 November 07. 


\begin{tabular}{|c|c|c|c|c|c|c|c|c|}
\hline \multirow[t]{2}{*}{ Correlates } & \multicolumn{2}{|c|}{ 30-day Specific Phobia ${ }^{a}$} & \multicolumn{2}{|c|}{ Lifetime Specific Phobia ${ }^{b}$} & \multicolumn{2}{|c|}{$\begin{array}{l}\text { 12-month Specific } \\
\text { Phobia among } \\
\text { lifetime cases } c\end{array}$} & \multicolumn{2}{|c|}{$\begin{array}{l}\text { 30-day Specific } \\
\text { Phobia among 12- } \\
\text { month cases }\end{array}$} \\
\hline & OR & $(95 \% \mathrm{CI})$ & OR & $(95 \% \mathrm{CI})$ & OR & $(95 \% \mathrm{CI})$ & OR & $(95 \% \mathrm{CI})$ \\
\hline Finished secondary & $1.6^{*}$ & $(1.4-1.9)$ & $1.3^{*}$ & $(1.2-1.4)$ & $1.5^{*}$ & $(1.2-1.8)$ & $1.4^{*}$ & $(1.1-1.8)$ \\
\hline Some college & $1.4^{*}$ & $(1.2-1.7)$ & $1.2^{*}$ & $(1.1-1.3)$ & $1.4^{*}$ & $(1.1-1.8)$ & 1.2 & $(0.9-1.6)$ \\
\hline Finished college & \multicolumn{2}{|l|}{1.0} & \multicolumn{2}{|l|}{1.0} & \multicolumn{2}{|l|}{1.0} & \multicolumn{2}{|l|}{1.0} \\
\hline Education level difference ${ }^{d}$ & \multicolumn{2}{|c|}{$\chi^{2}{ }_{3}=102.1^{*} . \mathrm{P}<.001$} & \multicolumn{2}{|c|}{$\chi^{2}{ }_{3}=80.5^{*} . \mathrm{P}<.001$} & \multicolumn{2}{|c|}{$\chi^{2}{ }_{3}=37.1^{*} . \mathrm{P}<.001$} & \multicolumn{2}{|c|}{$\begin{array}{l}\chi^{2}{ }_{3}=13.0^{*} \cdot \mathrm{P}= \\
0.04\end{array}$} \\
\hline \multicolumn{9}{|l|}{ Household income } \\
\hline Low & $1.5^{*}$ & $(1.3-1.7)$ & $1.3^{*}$ & $(1.1-1.4)$ & $1.7^{*}$ & $(1.3-2.1)$ & 1.2 & $(1.0-1.5)$ \\
\hline Low-average & $1.2^{*}$ & $(1.1-1.4)$ & 1.1 & $(1.0-1.2)$ & 1.2 & $(0.9-1.4)$ & $1.4^{*}$ & $(1.1-1.7)$ \\
\hline High-average & 1.1 & $(1.0-1.3)$ & 1.0 & $(0.9-1.1)$ & 1.1 & $(0.9-1.3)$ & 1.2 & $(0.9-1.5)$ \\
\hline High & \multicolumn{2}{|l|}{1.0} & \multicolumn{2}{|l|}{1.0} & \multicolumn{2}{|l|}{1.0} & \multicolumn{2}{|l|}{1.0} \\
\hline Household income difference ${ }^{d}$ & \multicolumn{2}{|c|}{$\chi^{2}{ }_{3}=30.4^{*} \cdot \mathrm{P}<.001$} & \multicolumn{2}{|c|}{$\chi^{2}{ }_{3}=24.8^{*} . \mathrm{P}<.001$} & \multicolumn{2}{|c|}{$\chi^{2}{ }_{3}=24.0 * . P<.001$} & \multicolumn{2}{|c|}{$\chi^{2}{ }_{3}=6.2 . P=0.10$} \\
\hline $\mathrm{N}^{e}$ & \multicolumn{2}{|c|}{68517} & \multicolumn{2}{|c|}{2972757} & \multicolumn{2}{|c|}{5807} & \multicolumn{2}{|c|}{4256} \\
\hline \multicolumn{9}{|c|}{ Significant at the .05 level. 2 sided test. } \\
\hline \multicolumn{9}{|c|}{$a_{\text {These estimates are based on logistic regression models adjusted for age. gender and high income countries. }}$} \\
\hline \multicolumn{9}{|c|}{$b$ These estimates are based on survival models adjusted for age-cohorts. gender. person-years and high income countries. } \\
\hline \multicolumn{9}{|c|}{$\begin{array}{l}c_{\text {These estimates are based on logistic regression models adjusted for time since specific phobia onset. age of specific }} \\
\text { phobia onset. gender and high income countries. } \\
{ }^{d} \text { Chi square test of significant differences between blocks of sociodemographic variables. }\end{array}$} \\
\hline
\end{tabular}

\section{Appendix Table 6}

Severity of role impairment (Sheehan Disability Scale: SDS) associated with 12-month specific phobia, by country.

\begin{tabular}{|c|c|c|c|c|c|c|c|c|c|c|c|}
\hline \multirow[t]{3}{*}{ Country } & \multicolumn{10}{|c|}{ Proportion with severe role impairment (SDS score: 7-10) } & \multirow{3}{*}{$\begin{array}{l}\text { Number } \\
\text { of } 12- \\
\text { month } \\
\text { specific } \\
\text { phobia } \\
\text { cases }\end{array}$} \\
\hline & \multicolumn{2}{|c|}{ Home } & \multicolumn{2}{|c|}{ Work } & \multicolumn{2}{|c|}{$\underline{\text { Relationship }}$} & \multicolumn{2}{|c|}{$\underline{\text { Social }}$} & \multicolumn{2}{|c|}{$\underline{\mathrm{Any} a}$} & \\
\hline & $\%$ & & $\%$ & SE & $\%$ & SE & $\%$ & SE & $\%$ & SE & \\
\hline Low-Lower middle income ${ }^{d, e, f, g, h}$ & 8.3 & 1.1 & 7.9 & 0.9 & 5.0 & 0.7 & 5.9 & 0.8 & 13.3 & 1.1 & 1254 \\
\hline Colombia $d, e, f, g$ & 10.5 & 2.2 & 11.7 & 1.7 & 6.5 & 1.3 & 7.0 & 1.4 & 17.8 & 2.4 & 398 \\
\hline $\operatorname{Iraq} c, d$ & 15.3 & 4.0 & 11.2 & 3.9 & 10.7 & 3.2 & 11.4 & 3.5 & 18.3 & 3.6 & 163 \\
\hline Nigeria $f$ & 2.0 & 1.2 & 3.7 & 1.6 & 1.3 & 0.6 & 2.1 & 1.3 & 4.5 & 1.6 & 266 \\
\hline Peru & 10.0 & 2.3 & 9.4 & 2.6 & 6.6 & 1.6 & 6.6 & 1.6 & 21.2 & 3.1 & 178 \\
\hline PRC China $d, h$ & 12.5 & 4.4 & 8.2 & 3.1 & 3.1 & 1.6 & 9.6 & 4.0 & 16.0 & 4.5 & 99 \\
\hline PRC Shen Zhen & 3.2 & 1.3 & 1.2 & 0.6 & 2.0 & 0.9 & 2.1 & 1.0 & 4.2 & 1.5 & 150 \\
\hline Upper-middle income $e^{c, d, e}$ & 14.4 & 1.2 & 11.3 & 1.1 & 9.9 & 0.8 & 10.6 & 0.9 & 21.9 & 1.3 & 1630 \\
\hline $\mathrm{Brazil}^{c, d, e}$ & 20.7 & 2.6 & 14.7 & 2.3 & 13.1 & 1.4 & 13.5 & 1.8 & 27.7 & 2.7 & 572 \\
\hline Bulgaria & 10.7 & 1.9 & 9.2 & 1.6 & 7.7 & 1.7 & 10.3 & 2.3 & 16.2 & 2.2 & 218 \\
\hline Colombia (Medellin) $)^{d, e, f, g}$ & 16.8 & 2.9 & 18.9 & 3.2 & 11.0 & 2.9 & 10.6 & 2.9 & 28.2 & 3.9 & 271 \\
\hline Lebanon $c, d$ & 8.2 & 2.2 & 1.0 & 0.8 & 3.3 & 1.7 & 3.5 & 1.8 & 13.9 & 3.4 & 185 \\
\hline Mexico $g$ & 8.7 & 1.9 & 6.6 & 1.7 & 8.5 & 1.5 & 10.3 & 1.9 & 15.2 & 2.3 & 302 \\
\hline
\end{tabular}

Psychol Med. Author manuscript; available in PMC 2017 November 07. 


\begin{tabular}{|c|c|c|c|c|c|c|c|c|c|c|c|}
\hline \multirow[t]{3}{*}{ Country } & \multicolumn{10}{|c|}{ Proportion with severe role impairment (SDS score: 7-10) } & \multirow{3}{*}{$\begin{array}{l}\text { Number } \\
\text { of } 12- \\
\text { month } \\
\text { specific } \\
\text { phobia } \\
\text { cases }\end{array}$} \\
\hline & \multicolumn{2}{|c|}{ Home } & \multicolumn{2}{|c|}{ Work } & \multicolumn{2}{|c|}{$\underline{\text { Relationship }}$} & \multicolumn{2}{|c|}{$\underline{\text { Social }}$} & \multicolumn{2}{|c|}{$\underline{\mathrm{Any} a}$} & \\
\hline & $\%$ & & $\%$ & SE & $\%$ & SE & $\%$ & SE & $\%$ & SE & \\
\hline Romania & 10.9 & 4.4 & 12.6 & 4.5 & 11.3 & 3.9 & 10.0 & 3.1 & 23.0 & 5.3 & 82 \\
\hline High income $\mathrm{e}^{d, f, h}$ & 9.3 & 0.5 & 9.5 & 0.6 & 8.0 & 0.5 & 9.4 & 0.6 & 19.2 & 0.7 & 4256 \\
\hline Belgium $c, f, g$ & 15.9 & 2.7 & 6.4 & 2.5 & 15.5 & 5.5 & 14.5 & 5.3 & 30.7 & 5.5 & 117 \\
\hline France ${ }^{f}$ & 11.4 & 2.5 & 15.2 & 2.7 & 10.4 & 2.4 & 11.0 & 2.5 & 21.6 & 3.2 & 226 \\
\hline Germany $e, h$ & 7.0 & 1.9 & 8.4 & 1.8 & 7.3 & 1.9 & 12.2 & 2.2 & 18.1 & 2.8 & 248 \\
\hline Italy ${ }^{c}$ & 13.5 & 3.0 & 7.1 & 2.5 & 10.6 & 2.7 & 9.0 & 2.3 & 20.9 & 3.2 & 181 \\
\hline Japan $^{d, e}$ & 11.5 & 3.5 & 7.7 & 2.8 & 2.7 & 1.5 & 2.5 & 1.9 & 17.4 & 4.1 & 96 \\
\hline New Zealand & 6.8 & 0.9 & 7.2 & 1.0 & 6.1 & 0.8 & 7.1 & 0.9 & 15.5 & 1.2 & 1098 \\
\hline Northern Ireland ${ }^{h}$ & 9.4 & 1.8 & 12.3 & 2.7 & 8.9 & 1.8 & 12.8 & 2.1 & 22.4 & 2.8 & 336 \\
\hline Poland ${ }^{c, d}$ & 11.3 & 2.2 & 7.6 & 2.1 & 6.3 & 1.7 & 8.6 & 2.2 & 16.9 & 2.5 & 250 \\
\hline Portugal & 7.6 & 1.4 & 9.9 & 1.6 & 7.5 & 1.2 & 7.8 & 1.5 & 19.0 & 2.4 & 370 \\
\hline Spain $e, g$ & 13.1 & 2.8 & 13.8 & 3.6 & 9.5 & 3.0 & 8.4 & 2.5 & 26.0 & 4.3 & 206 \\
\hline Spain $\left(\right.$ Murcia) ${ }^{c}$ & 10.9 & 4.9 & 15.0 & 4.9 & 14.4 & 5.1 & 15.5 & 4.3 & 17.7 & 4.4 & 118 \\
\hline The Netherlands $e, g$ & 13.3 & 2.4 & 11.8 & 2.5 & 7.0 & 2.1 & 5.3 & 2.3 & 22.6 & 3.7 & 135 \\
\hline The United States $h$ & 8.6 & 1.2 & 9.2 & 1.1 & 7.8 & 1.2 & 10.7 & 1.4 & 18.7 & 1.8 & 875 \\
\hline All countries combined ${ }^{d, e, f, h}$ & 10.3 & 0.5 & 9.6 & 0.4 & 7.9 & 0.4 & 9.0 & 0.4 & 18.7 & 0.6 & 7140 \\
\hline Comparison between countries $b$ & \multicolumn{2}{|c|}{$\begin{array}{l}\chi^{2}{ }_{24}= \\
4.00^{*}, p< \\
001\end{array}$} & \multicolumn{2}{|c|}{$\begin{array}{l}\chi^{2}{ }_{24}= \\
4.8^{*}, P< \\
001\end{array}$} & \multicolumn{2}{|c|}{$\begin{array}{l}\chi^{2} 24=4.5^{*} \\
P<.001\end{array}$} & \multicolumn{2}{|c|}{$\begin{array}{l}\chi^{2}{ }_{24}= \\
3.5^{3}, \mathrm{P}< \\
001\end{array}$} & \multicolumn{2}{|c|}{$\begin{array}{l}\chi^{2}{ }^{24}= \\
4.9^{*}, P< \\
001\end{array}$} & \\
\hline $\begin{array}{l}\text { Comparison between low, middle } \\
\text { and high income country groups } b\end{array}$ & \multicolumn{2}{|c|}{$\begin{array}{l}\chi^{2} 2_{*}= \\
9.2^{*}, p<. \\
001\end{array}$} & \multicolumn{2}{|c|}{$\begin{array}{l}\chi_{2}^{2}=2.8 \\
P=0.06\end{array}$} & \multicolumn{2}{|c|}{$\begin{array}{l}\chi^{2}{ }_{2}=11.2^{*} \\
\mathrm{P}<.001\end{array}$} & \multicolumn{2}{|c|}{$\begin{array}{l}\chi^{2} 2_{2}= \\
8.6, P< \\
001\end{array}$} & \multicolumn{2}{|c|}{$\begin{array}{l}\chi^{2} 2= \\
13.5^{*}, P< \\
001\end{array}$} & \\
\hline
\end{tabular}

* Significant at the .05 level, 2 sided test.

${ }^{a}$ Highest severity category across 4 SDS role domains.

${ }^{b}$ Chi-square test of homogeneity to determine if there is variation in impairment severity across countries.

cMcNemar's chi-square test to determine if there is a significant difference at the .05 level for home vs work impairment, ${ }^{d}$ McNemar's chi-square test to determine if there is a significant difference at the .05 level for home vs relationship impairment,

e McNemar's chi-square test to determine if there is a significant difference at the .05 level for home vs social impairment, $f$ McNemar's chi-square test to determine if there is a significant difference at the .05 level for work vs relationship impairment,

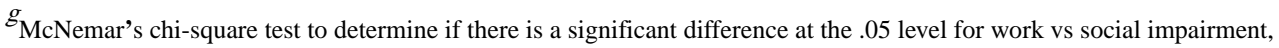

h McNemar's chi-square test to determine if there is a significant difference at the .05 level for relationship vs social impairment for each row entry. For example, subscript ' $\mathrm{d}$ ' for Colombia indicates that the proportion with severe impairment associated with specific phobia is significantly higher for home than relationship. 


\section{Appendix Table 7}

Days out of role due to 12 -month specific phobia ${ }^{b}$ by role impairment.

\begin{tabular}{lllllllll}
\hline & \multicolumn{4}{c}{ Days out of role due to 12-month specific phobia } \\
\cline { 2 - 8 } Sheehan Disability Domain & \multicolumn{4}{c}{$\begin{array}{c}\text { Not severe } \\
\text { (Score: 0-6) }\end{array}$} & \multicolumn{5}{c}{$\begin{array}{c}\text { Severe } \\
\text { (Score: 7-10) }\end{array}$} & F-test. p-value \\
& $\mathbf{n}$ & Mean & SE & n & Mean & SE & \\
\hline Home & 3063 & 7.1 & 0.7 & 727 & 34.6 & 3.8 & $57.9^{*} . \mathrm{P}<.001$ \\
Work & 3125 & 6.0 & 0.6 & 659 & 42.1 & 4.3 & $75.0^{*} . \mathrm{P}<.001$ \\
Relationship & 3254 & 6.4 & 0.7 & 547 & 47.9 & 5.0 & $75.5^{*} . \mathrm{P}<.001$ \\
Social & 3174 & 5.9 & 0.6 & 630 & 45.1 & 4.5 & $79.5^{*} . \mathrm{P}<.001$ \\
Any ${ }^{a}$ & 2493 & 3.8 & 0.5 & 1313 & 29.1 & 2.6 & $104.6^{*} . \mathrm{P}<.001$ \\
\hline
\end{tabular}

${ }^{a}$ Mean days out of role presented for subgroups of respondents defined by their highest severity category across the 4 sheehan disability domains (home. work. relationship and social).

${ }^{b}$ Mean (SE) days out of role due to 12-month specific phobia: 12.2 (0.9) days.

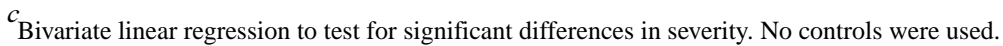

\section{Appendix Table 8}

Among those with 12-month specific phobia. percent reporting treatment in the past 12 months by Sheehan impairment severity and country income categories.

\begin{tabular}{|c|c|c|c|c|c|c|c|c|}
\hline \multirow{3}{*}{ Sector of treatment } & \multicolumn{8}{|c|}{ Sheehan Disability Scale Category $a$} \\
\hline & \multicolumn{2}{|c|}{$\begin{array}{l}\text { Mild Impairment } \\
\text { (Score: 1-3) }\end{array}$} & \multicolumn{2}{|c|}{$\begin{array}{l}\text { Moderate Impairment } \\
\text { (Score: 4-6) }\end{array}$} & \multicolumn{2}{|c|}{$\begin{array}{c}\text { Severe Impairment } \\
\text { (Score: 7-10) }\end{array}$} & \multicolumn{2}{|c|}{ Any impairment } \\
\hline & $\%$ & SE & $\%$ & SE & $\%$ & SE & $\%$ & SE \\
\hline \multicolumn{9}{|l|}{ Specialty mental health $b$} \\
\hline Total & 8.6 & 0.7 & 9.8 & 0.9 & 16.6 & 1.2 & 10.4 & 0.4 \\
\hline Low-lower middle income & 3.0 & 1.2 & 5.9 & 1.9 & 5.7 & 1.7 & 4.4 & 0.8 \\
\hline Upper-middle income & 8.5 & 1.4 & 8.4 & 1.8 & 10.4 & 1.8 & 9.0 & 0.8 \\
\hline High income & 11.2 & 1.1 & 11.6 & 1.3 & 21.7 & 1.7 & 12.9 & 0.6 \\
\hline \multicolumn{9}{|l|}{ General medical $^{c}$} \\
\hline Total & 14.0 & 0.9 & 15.1 & 1.1 & 21.0 & 1.3 & 14.9 & 0.5 \\
\hline Low-lower middle income & 4.1 & 1.1 & 4.2 & 1.3 & 7.7 & 2.6 & 4.5 & 0.7 \\
\hline Upper-middle income & 5.0 & 0.9 & 8.8 & 1.8 & 9.7 & 2.0 & 6.8 & 0.7 \\
\hline High income & 21.8 & 1.4 & 20.7 & 1.5 & 28.8 & 1.8 & 21.4 & 0.7 \\
\hline \multicolumn{9}{|l|}{ Health care ${ }^{d}$} \\
\hline Total & 19.0 & 1.0 & 20.7 & 1.2 & 30.1 & 1.5 & 21.0 & 0.6 \\
\hline Low-lower middle income & 6.6 & 1.5 & 10.1 & 2.3 & 13.2 & 2.9 & 8.4 & 1.1 \\
\hline Upper-middle income & 12.6 & 1.5 & 15.9 & 2.5 & 17.9 & 2.4 & 14.4 & 0.9 \\
\hline High income & 26.9 & 1.6 & 25.6 & 1.6 & 39.3 & 2.0 & 27.6 & 0.8 \\
\hline \multicolumn{9}{|l|}{ Human services $e$} \\
\hline Total & 2.4 & 0.4 & 2.4 & 0.4 & 4.2 & 0.6 & 2.6 & 0.2 \\
\hline Low-lower middle income & - & - & 1.3 & 0.7 & - & - & 0.9 & 0.3 \\
\hline Upper-middle income & 1.7 & 0.9 & - & - & 2.5 & 0.9 & 1.2 & 0.3 \\
\hline
\end{tabular}

Psychol Med. Author manuscript; available in PMC 2017 November 07. 


\begin{tabular}{|c|c|c|c|c|c|c|c|c|}
\hline \multirow{3}{*}{ Sector of treatment } & \multicolumn{8}{|c|}{ Sheehan Disability Scale Category ${ }^{a}$} \\
\hline & \multicolumn{2}{|c|}{$\begin{array}{l}\text { Mild Impairment } \\
\quad \text { (Score: 1-3) }\end{array}$} & \multicolumn{2}{|c|}{$\begin{array}{l}\text { Moderate Impairment } \\
\quad \text { (Score: 4-6) }\end{array}$} & \multicolumn{2}{|c|}{$\begin{array}{l}\text { Severe Impairment } \\
\text { (Score: 7-10) }\end{array}$} & \multicolumn{2}{|c|}{ Any impairment } \\
\hline & $\%$ & SE & $\%$ & SE & $\%$ & SE & $\%$ & SE \\
\hline High income & 3.5 & 0.6 & 3.3 & 0.6 & 5.3 & 0.8 & 3.7 & 0.4 \\
\hline \multicolumn{9}{|l|}{$\mathrm{CAM}^{f}$} \\
\hline Total & 3.1 & 0.5 & 3.0 & 0.5 & 3.8 & 0.6 & 3.0 & 0.2 \\
\hline Low-lower middle income & 1.0 & 0.5 & - & - & 2.1 & 1.1 & 1.1 & 0.3 \\
\hline Upper-middle income & 2.6 & 1.3 & 1.1 & 0.6 & 1.3 & 0.6 & 1.8 & 0.5 \\
\hline High income & 4.3 & 0.7 & 4.2 & 0.7 & 5.4 & 0.9 & 4.1 & 0.4 \\
\hline \multicolumn{9}{|l|}{ Non health care ${ }^{g}$} \\
\hline Total & 4.9 & 0.6 & 4.8 & 0.6 & 6.7 & 0.7 & 5.0 & 0.3 \\
\hline Low-lower middle income & 1.3 & 0.6 & 2.6 & 1.0 & 3.6 & 1.6 & 1.9 & 0.4 \\
\hline Upper-middle income & 4.3 & 1.5 & 1.3 & 0.7 & 3.5 & 1.0 & 2.9 & 0.5 \\
\hline High income & 6.6 & 0.9 & 6.7 & 0.9 & 8.9 & 1.1 & 6.8 & 0.5 \\
\hline \multicolumn{9}{|l|}{ Any treatment $h$} \\
\hline Total & 21.1 & 1.1 & 22.8 & 1.3 & 32.5 & 1.5 & 23.1 & 0.6 \\
\hline Low-lower middle income & 7.5 & 1.6 & 11.7 & 2.5 & 15.0 & 2.9 & 9.6 & 1.1 \\
\hline Upper-middle income & 14.9 & 1.9 & 17.0 & 2.6 & 19.7 & 2.5 & 16.0 & 1.0 \\
\hline High income & 29.6 & 1.7 & 28.2 & 1.7 & 42.0 & 2.0 & 30.1 & 0.8 \\
\hline \multicolumn{9}{|c|}{$\begin{array}{l}b \text { The mental health specialist sector. which includes psychiatrist and non-psychiatrist mental health specialists (psychiatrist. } \\
\text { psychologist or other non-psychiatrist mental health professional; social worker or counsellor in a mental health specialty } \\
\text { setting; use of a mental health helpline; or overnight admissions for a mental health or drug or alcohol problems. with a } \\
\text { presumption of daily contact with a psychiatrist). }\end{array}$} \\
\hline \multicolumn{9}{|c|}{$\begin{array}{l}c_{\text {The general medical sector (general practitioner. other medical doctor. nurse. occupational therapist or any healthcare }} \\
\text { professional). } \\
d_{\text {The mental health specialist sector or the general medical sector. }}\end{array}$} \\
\hline \multicolumn{9}{|c|}{$\begin{array}{l}\text { e The human services sector (religious or spiritual advisor or social worker or counsellor in any setting other than a specialty } \\
\text { mental health setting). }\end{array}$} \\
\hline
\end{tabular}

\section{References}

Alonso J, Angermeyer MC, Bernert S, Bruffaerts R, Brugha TS, Bryson H, de Girolamo G, Graaf R, Demyttenaere K, Gasquet I, Haro JM, Katz SJ, Kessler RC, Kovess V, Lépine JP, Ormel J, Polidori G, Russo LJ, Vilagut G, Almansa J, Arbabzadeh-Bouchez S, Autonell J, Bernal M, Buist-Bouwman MA, Codony M, Domingo-Salvany A, Ferrer M, Joo SS, Martínez-Alonso M, Matschinger H, Mazzi F, Morgan Z, Morosini P, Palacín C, Romera B, Taub N, Vollebergh WA, ESEMeD/ MHEDEA. Investigators, European Study of the Epidemiology of Mental Disorders (ESEMeD) Project. (2004). 12-Month comorbidity patterns and associated factors in Europe: results from the European Study of the Epidemiology of Mental Disorders (ESEMeD) project. Acta Psychiatrica Scandinavica Supplement. 2000; 420:28-37. 
Andrade LH, Alonso J, Mneimneh Z, Wells JE, Al-Hamzawi A, Borges G, Bromet E, Bruffaerts R, de Girolamo G, de Graaf R, Florescu S, Gureje O, Hinkov HR, Hu C, Huang Y, Hwang I, Jin R, Karam EG, Kovess-Masfety V, Levinson D, Matschinger H, O’Neill S, Posada-Villa J, Sagar R, Sampson NA, Sasu C, Stein DJ, Takeshima T, Viana MC, Xavier M, Kessler RC. Barriers to mental health treatment: results from the WHO World Mental Health surveys. Psychological Medicine. 2014; 44:1303-17. [PubMed: 23931656]

Angermeyer MC, Dietrich S. Public beliefs about and attitudes towards people with mental illness: a review of population studies. Acta Psychiatrica Scandinavica. 2006; 113:163-179. [PubMed: 16466402]

Angst J, Paksarian D, Cui L, Merikangas KR, Hengartner MP, Ajdacic-Gross V, Rössler W. The epidemiology of common mental disorders from age 20 to 50: results from the prospective Zurich cohort Study. Epidemiology and Psychiatric Science. 2016; 25(1):24-32.

Becker ES, Rinck M, Türke V, Kause P, Goodwin R, Neumer S, Margraf J. Epidemiology of specific phobia subtypes: findings from the Dresden Mental Health Study. European Psychiatry. 2007; 22(2):69-74. [PubMed: 17157482]

Bijl RV, Ravelli A, van Zessen G. Prevalence of psychiatric disorder in the general population: results of the Netherlands Mental Health Survey and Incidence Study (NEMESIS). Social Psychiatry and Psychiatric Epidemiology. 1998; 33:587-595. [PubMed: 9857791]

Bijl RV, De Graaf R, Ravelli A, Smit F, Vollebergh WA, Netherlands Mental Health Survey and Incidence Study. Gender and age-specific first incidence of DSM-III-R psychiatric disorders in the general population. Results from the Netherlands Mental Health Survey and Incidence Study (NEMESIS). Social Psychiatry and Psychiatric Epidemiology. 2002; 37(8):372-9. [PubMed: 12195544]

Bittner A, Goodwin RD, Wittchen HU, Beesdo K, Höfler M, Lieb R. What characteristics of primary anxiety disorders predict subsequent major depressive disorder? Journal of Clinical Psychiatry. 2004; 65(5):618-26. [PubMed: 15163247]

Choy Y, Fyer AJ, Lipsitz JD. Treatment of specific phobia in adults. Clinical Psychology Review. 2007; 27(3):266-86. [PubMed: 17112646]

Clement S, Schauman O, Graham T, Maggioni F, Evans-Lacko S, Bezborodovs N, Morgan C, Rüsch N, Brown JS, Thornicroft G. What is the impact of mental health related stigma on help-seeking? A systematic review of quantitative and qualitative studies. Psychological Medicine. 2015; 45:1127. [PubMed: 24569086]

Comer JS, Blanco C, Hasin DS, Liu SM, Grant BF, Turner JB, Olfson M. Health-related quality of life across the anxiety disorders: results from the national epidemiologic survey on alcohol and related conditions (NESARC). Journal of Clinical Psychiatry. 2011; 72(1):43-50. [PubMed: 20816036]

Curtis GC, Magee WJ, Eaton WW, Wittchen HU, Kessler RC. Specific fears and phobias. Epidemiology and classification. British Journal of Psychiatry. 1998; 173:212-217. [PubMed: 9926096]

de Graaf R, ten Have M, van Gool C, van Dorsselaer S. Prevalence of mental disorders and trends from 1996 to 2009. Results from the Netherlands Mental Health Survey and Incidence Study-2. Social Psychiatry and Psychiatric Epidemiology. 2012; 47:303-213. [PubMed: 21286683]

Depla MF, ten Have ML, van Balkom AJ, de Graaf R. Specific fears and phobias in the general population: results from the Netherlands Mental Health Survey and Incidence Study (NEMESIS). Social Psychiatry and Psychiatric Epidemiology. 2008; 43:200-8. [PubMed: 18060338]

Fredrikson M, Annas P, Fischer H, Wik G. Gender and age differences in the prevalence of specific fears and phobias. Behaviour Research and Therapy. 1996; 34(1):33-9. [PubMed: 8561762]

Goisman RM, Allsworth J, Rogers MP, Warshaw MG, Goldenberg I, Vasile RG, Rodriguez-Villa F, Mallya G, Keller MB. Simple phobia as a comorbid anxiety disorder. Depression and Anxiety. 1998; 7(3):105-12. [PubMed: 9656090]

Goodwin RD. Anxiety disorders and the onset of depression among adults in the community. Psychological Medicine. 2002; 32:1121-1124. [PubMed: 12214791]

Grant BF, Goldstein RB, Chou SP, Huang B, Stinson FS, Dawson DA, Saha TD, Smith SM, Pulay AJ, Pickering RP, Ruan WJ, Compton WM. Sociodemographic and psychopathologic predictors of first incidence of DSM-IV substance use, mood and anxiety disorders: results from the Wave 2 
National Epidemiologic Survey on Alcohol and Related Conditions. Molecular Psychiatry. 2009; 14(11):1051-66. [PubMed: 18427559]

Grenier S, Schuurmans J, Goldfarb M, Préville M, Boyer R, O’Connor K, Potvin O, Hudon C, Scientific committee of the ESA study. The epidemiology of specific phobia and subthreshold fear subtypes in a community-based sample of older adults. Depression and Anxiety. 2011; 28(6):45663. [PubMed: 21400642]

Halli, SS., Rao, KV., Halli, SS. Advanced Techniques of Population Analysis. Plenum; NY: 1992. 1992

Harkness, J., Pennell, BE., Villar, A., Gebler, N., Aguilar-Gaxiola, S., Bilgen, I. Translation procedures and translation assessment in the World Mental Health Survey Initiative. In: Kessler, RC., Üstün, TB., editors. The WHO World Mental Health Surveys: Global Perspectives on the Epidemiology of Mental Disorders. Cambridge University Press; New York, NY: 2008. p. 91-113.

Haro JM, Arbabzadeh-Bouchez S, Brugha TS, de Girolamo G, Guyer ME, Jin R, Lepine JP, Mazzi F, Reneses B, Vilagut G, Sampson NA, Kessler RC. Concordance of the Composite International Diagnostic Interview Version 3.0 (CIDI 3.0) with standardized clinical assessments in the WHO World Mental Health surveys. International Journal of Methods in Psychiatric Research. 2006; 15:167-80. [PubMed: 17266013]

Hinton DE, Pollack MH. Introduction to the special issue: anxiety disorders in cross-cultural perspective. CNS Neuroscience \& Therapeutics. 2009; 15:207-9. [PubMed: 19691539]

Hofmann SG, Hinton DE. Cross-cultural aspects of anxiety disorders. Current Psychiatry Reports. 2014; 16:450. [PubMed: 24744049]

Iza M, Olfson M, Vermes D, Hoffer M, Wang S, Blanco C. Probability and predictors of first treatment contact for anxiety disorders in the United States: analysis of data from the National Epidemiologic Survey on Alcohol and Related Conditions (NESARC). Journal of Clinical Psychiatry. 2013; 74(11):1093-100. [PubMed: 24330896]

Kessler RC, Berglund P, Demler O, Jin R, Merikangas KR, Walters EE. Lifetime prevalence and ageof-onset distributions of DSM-IV disorders in the national comorbidity survey replication. Archives of General Psychiatry. 2005; 62:593-602. [PubMed: 15939837]

Kessler RC, Crum RM, Warner LA, Nelson CB, Schulenberg J, Anthony JC. Lifetime co-occurrence of DSM-III-R alcohol abuse and dependence with other psychiatric disorders in the National Comorbidity Survey. Archives of General Psychiatry. 1997; 54:313-21. [PubMed: 9107147]

Kessler RC, McGonagle KA, Zhao S, Nelson CB, Hughes M, Eshleman S, Wittchen H-U, Kendler KS. Lifetime and 12 month prevalence of DSM-III-R psychiatric disorders in the United States: results from the National Comorbidity Survey. Archives of General Psychiatry. 1994; 51:8-19. [PubMed: 8279933]

Kessler RC, Nelson CB, McGonagle KA, Liu J, Swartz M, Blazer DG. Comorbidity of DSM-III-R major depressive disorder in the general population: results from the US National Comorbidity Survey. British Journal of Psychiatry Supplement. 1996; 30:17-30.

Kessler RC, Ustun TB. The World Mental Health (WMH) Survey Initiative Version of the World Health Organization (WHO) Composite International Diagnostic Interview (CIDI). International Journal of Methods in Psychiatric Research. 2004; 13:93-121. [PubMed: 15297906]

Kessler, RC., Üstün, TB. The WHO World Mental Health Surveys: Global Perspectives on the Epidemiology of Mental Disorders. Cambridge University Press; New York, NY: 2008.

LeBeau RT, Glenn D, Liao B, Wittchen HU, Beesdo-Baum K, Ollendick T, Craske MG. Specific phobia: a review of DSM-IV specific phobia and preliminary recommendations for DSM-V. Depression and Anxiety. 2010; 27:148-167. [PubMed: 20099272]

Lee S, Juon HS, Martinez G, Hsu CE, Robinson ES, Bawa J, Ma GX. Model minority at risk: expressed needs of mental health by Asian American young adults. Journal of Community Health. 2009; 34:144-52. [PubMed: 18931893]

Leon AC, Olfson M, Portera L, Farber L, Sheehan DV. Assessing psychiatric impairment in primary care with the Sheehan Disability Scale. International Journal of Psychiatry in Medicine. 1997; 27:93-105. [PubMed: 9565717]

Levinson D, Lakoma MD, Petukhova M, Schoenbaum M, Zaslavsky AM, Angermeyer M, Borges G, Bruffaerts R, de Girolamo G, de Graaf R, Gureje O, Haro JM, Hu C, Karam AN, Kawakami N, 
Lee S, Lepine JP, Browne MO, Okoliyski M, Posada-Villa J, Sagar R, Viana MC, Williams DR, Kessler RC. Associations of serious mental illness with earnings: results from the WHO World Mental Health surveys. British Journal of Psychiatry. 2010; 197:114-121. [PubMed: 20679263]

Lieb R, Miché M, Gloster AT, Beesdo-Baum K, Meyer AH, Wittchen HU. Impact of specific phobia on the risk of onset of mental disorders: a 10-year prospective longitudinal community study of adolescents and young adults. Depression and Anxiety. 2016; 33(7):667-75. [PubMed: 26990012]

Magee WJ, Eaton WW, Wittchen HU, McGonagle KA, Kessler RC. Agoraphobia, simple phobia, and social phobia in the national comorbidity survey. Archives of General Psychiatry. 1996; 53:159_ 168. [PubMed: 8629891]

Marques L, Robinaugh DJ, LeBlanc NJ, Hinton D. Cross-cultural variations in the prevalence and presentation of anxiety disorders. Expert Review of Neurotherapeutics. 2011; 11:313-22. [PubMed: 21306217]

McBain R, Norton DJ, Morris J, Yasamy MT, Betancourt TS. The role of health systems factors in facilitating access to psychotropic medicines: a cross-sectional analysis of the WHO-AIMS in 63 low- and middle-income countries. PLoS Medicine. 2012; 9:e1001166. [PubMed: 22303288]

Moffitt TE, Caspi A, Taylor A, Kokaua J, Milne BJ, Polanczyk G, Poulton R. How common are common mental disorders? Evidence that lifetime prevalence rates are doubled by prospective versus retrospective ascertainment. Psychological Medicine. 2010; 40:899-909. [PubMed: 19719899]

Ormel J, Petukhova M, Chatterji S, Aguilar-Gaxiola S, Alonso J, Angermeyer MC, Bromet EJ, Burger H, Demyttenaere K, de Girolamo G, Haro JM, Hwang I, Karam E, Kawakami N, Lépine JP, Medina-Mora ME, Posada-Villa J, Sampson N, Scott K, Ustün TB, Von Korff M, Williams DR, Zhang M, Kessler RC. Disability and treatment of specific mental and physical disorders across the world. British Journal of Psychiatry. 2008; 192(5):368-75. [PubMed: 18450663]

Palazzo MC, Dell'Osso B, Altamura AC, Stein DJ, Baldwin DS. Health literacy and the pharmacological treatment of anxiety disorders: a systematic review. Human Psychopharmacology. 2014; 29:211-5. [PubMed: 24911573]

Saxena S, Thornicroft G, Knapp M, Whiteford H. Resources for mental health: scarcity, inequity, and inefficiency. Lancet. 2007; 370:878-89. [PubMed: 17804062]

Semrau M, Evans-Lacko S, Koschorke M, Ashenafi L, Thornicroft G. Stigma and discrimination related to mental illness in low- and middle-income countries. Epidemiology and Psychiatric Science. 2015; 24:382-94.

Sigström R, Skoog I, Karlsson B, Nilsson J, Östling S. Nine-year follow-up of specific phobia in a population sample of older people. Depression and Anxiety. 2016; 33(4):339-46. [PubMed: 26645153]

Stinson FS, Dawson DA, Chou SP, Smith S, Goldstein RB, Ruan WJ, Grant BF. The epidemiology of DSM-IV specific phobia in the USA: results from the National Epidemiologic Survey on Alcohol and Related Conditions. Psychological Medicine. 2007; 37(7):1047-59. [PubMed: 17335637]

ten Have M, de Graaf R, van Dorsselaer S, Beekman A. Lifetime treatment contact and delay in treatment seeking after first onset of a mental disorder. Psychiatric Services. 2013; 64(10):981-9. [PubMed: 23820725]

Trumpf J, Margraf J, Vriends N, Meyer AH, Becker ES. Specific phobia predicts psychopathology in young women. Social Psychiatry and Psychiatric Epidemiology. 2010; 45(12):1161-1166. [PubMed: 19888542]

Wells JE, Browne MA, Scott KM, McGee MA, Baxter J, Kokaua J, New Zealand Mental Health Survey Research Team. Prevalence, interference with life and severity of 12 month DSM-IV disorders in Te Rau Hinengaro: the New Zealand Mental Health Survey. Australian and New Zealand Journal of Psychiatry. 2006; 40(10):845-854. [PubMed: 16959010]

Wolter, KM. Introduction to Variance Estimation. Springer-Verlag; New York, NY: 1985.

World Bank. World Bank Data and Statistics. World Bank; 2008.

Zimmermann P, Wittchen HU, Höfler M, Pfister H, Kessler RC, Lieb R. Primary anxiety disorders and the development of subsequent alcohol use disorders: a 4-year community study of adolescents and young adults. Psychological Medicine. 2003; 33(7):1211-22. [PubMed: 14580076] 


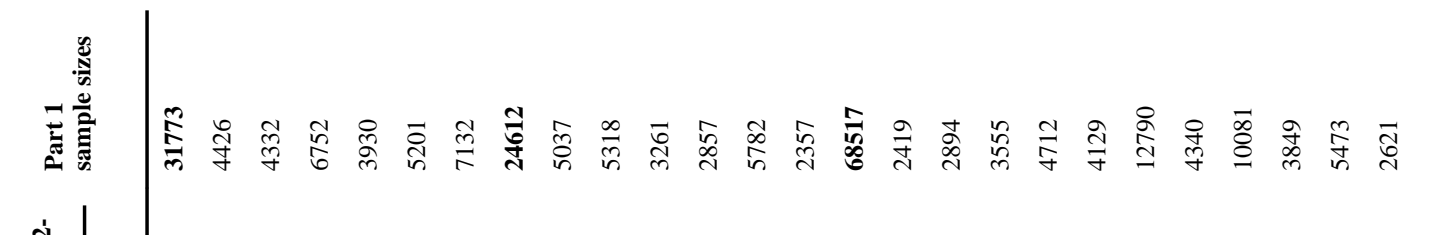




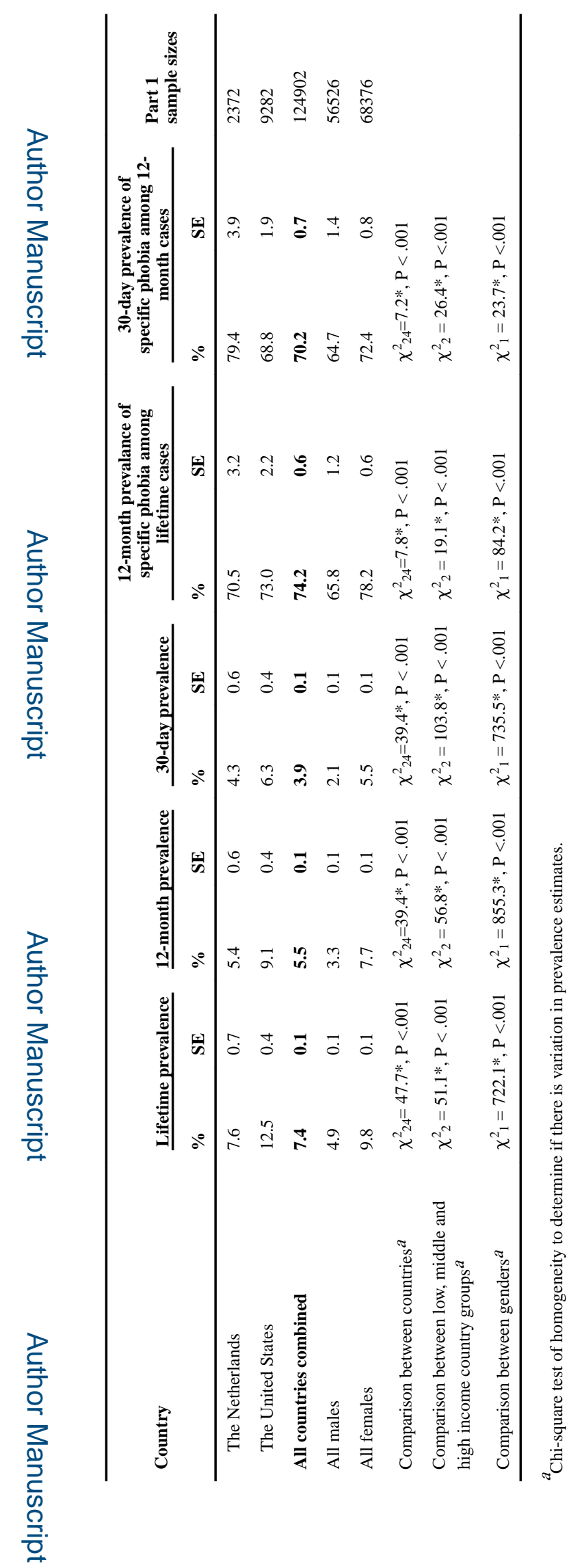

Psychol Med. Author manuscript; available in PMC 2017 November 07. 


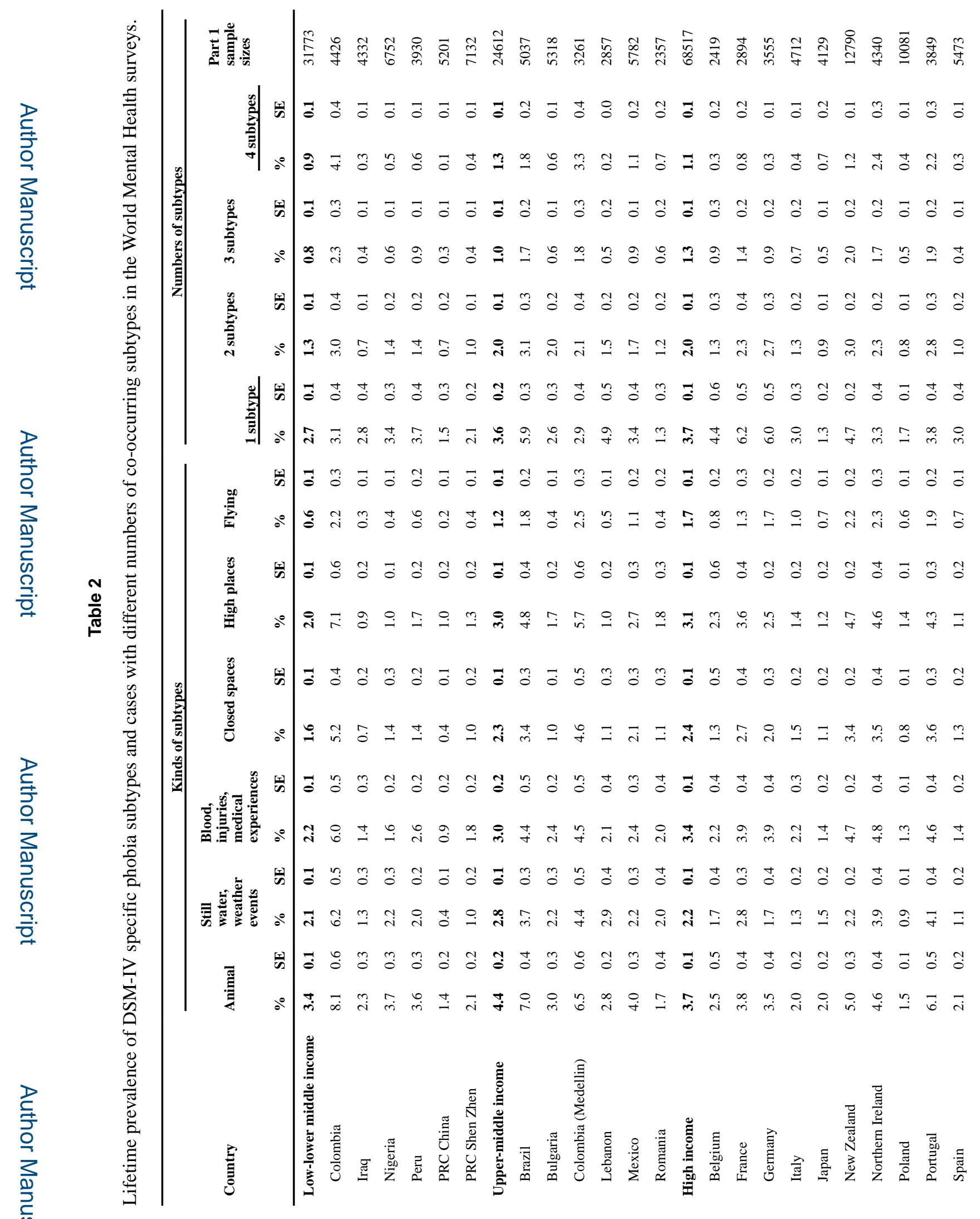

Psychol Med. Author manuscript; available in PMC 2017 November 07. 


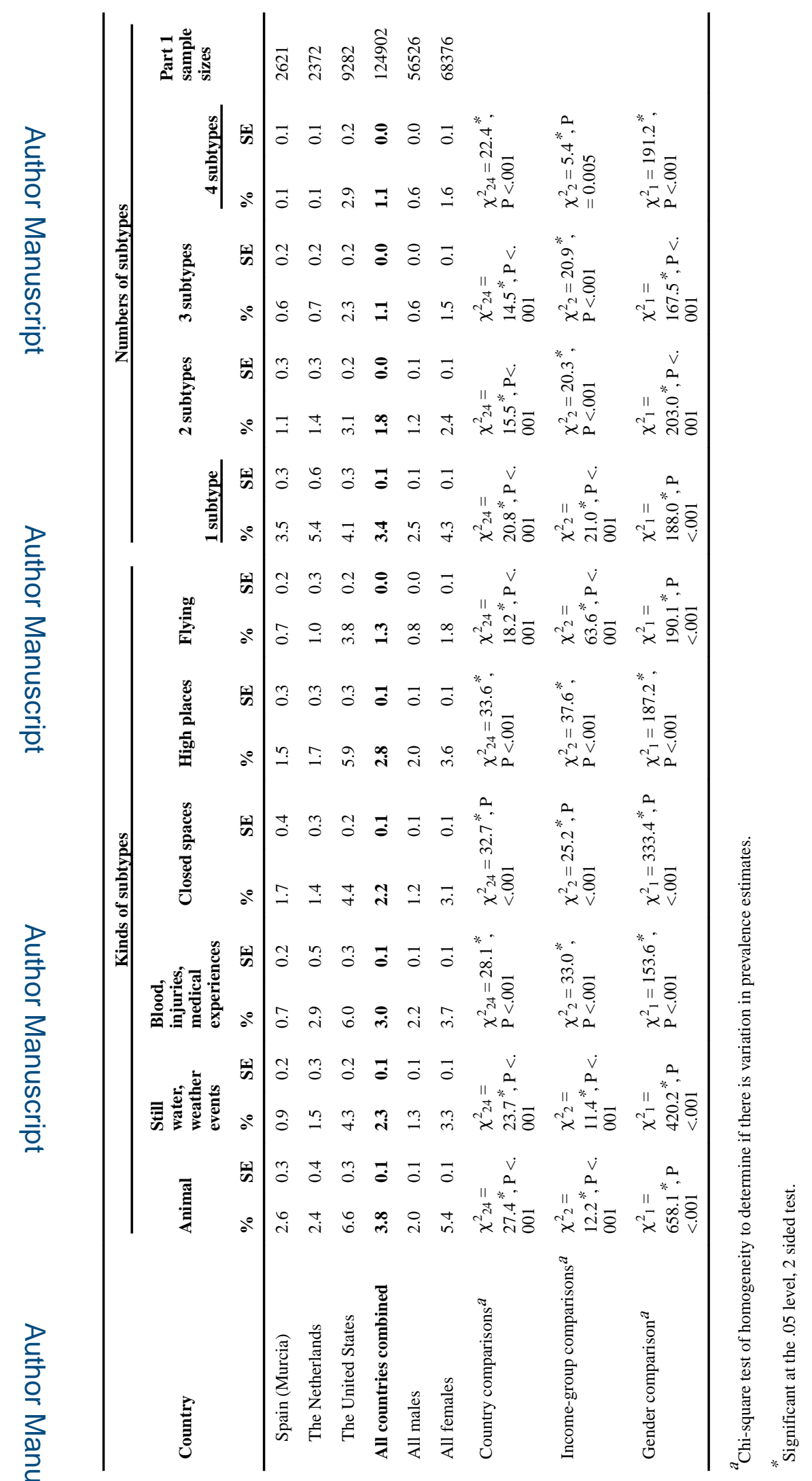




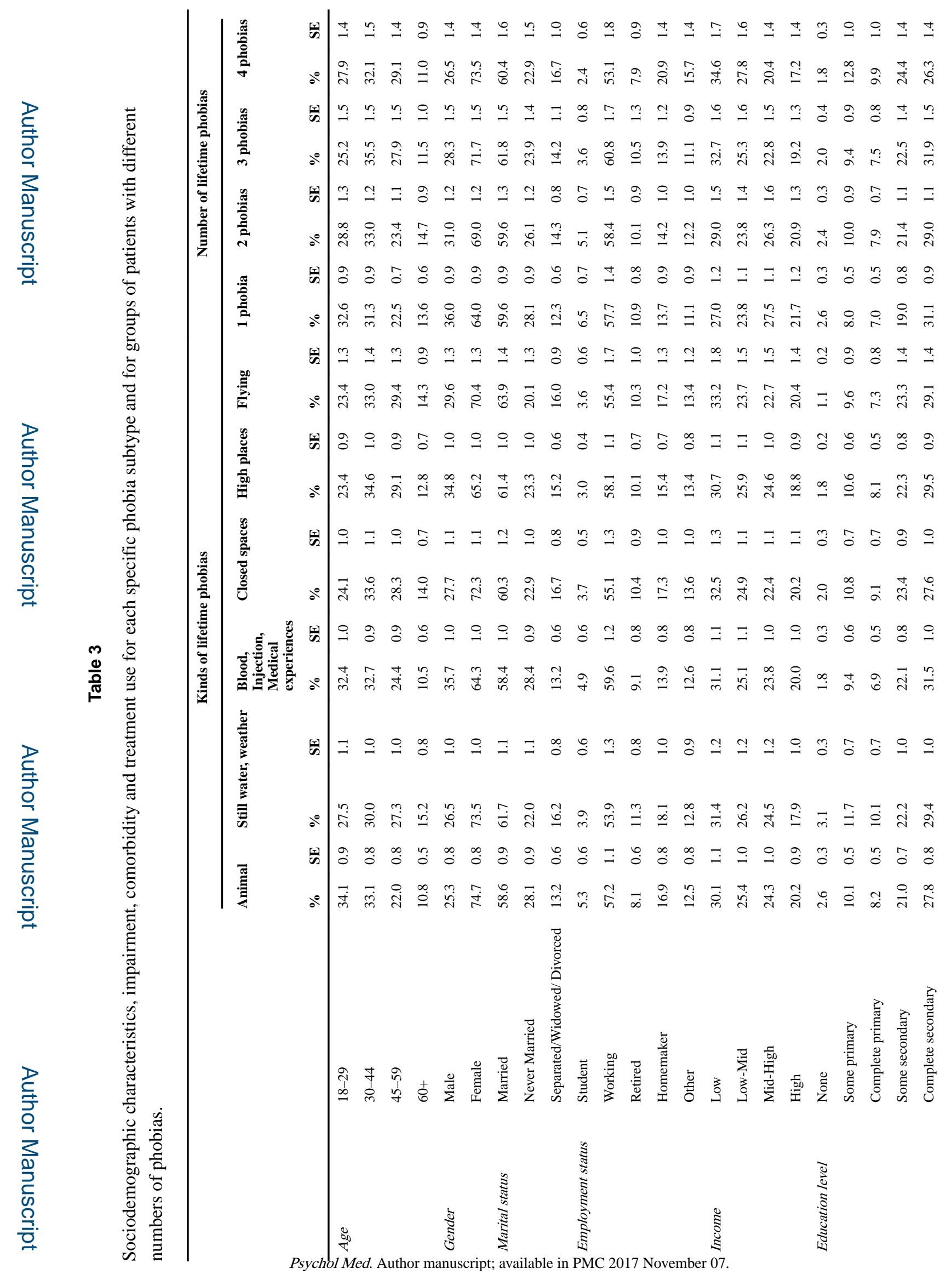




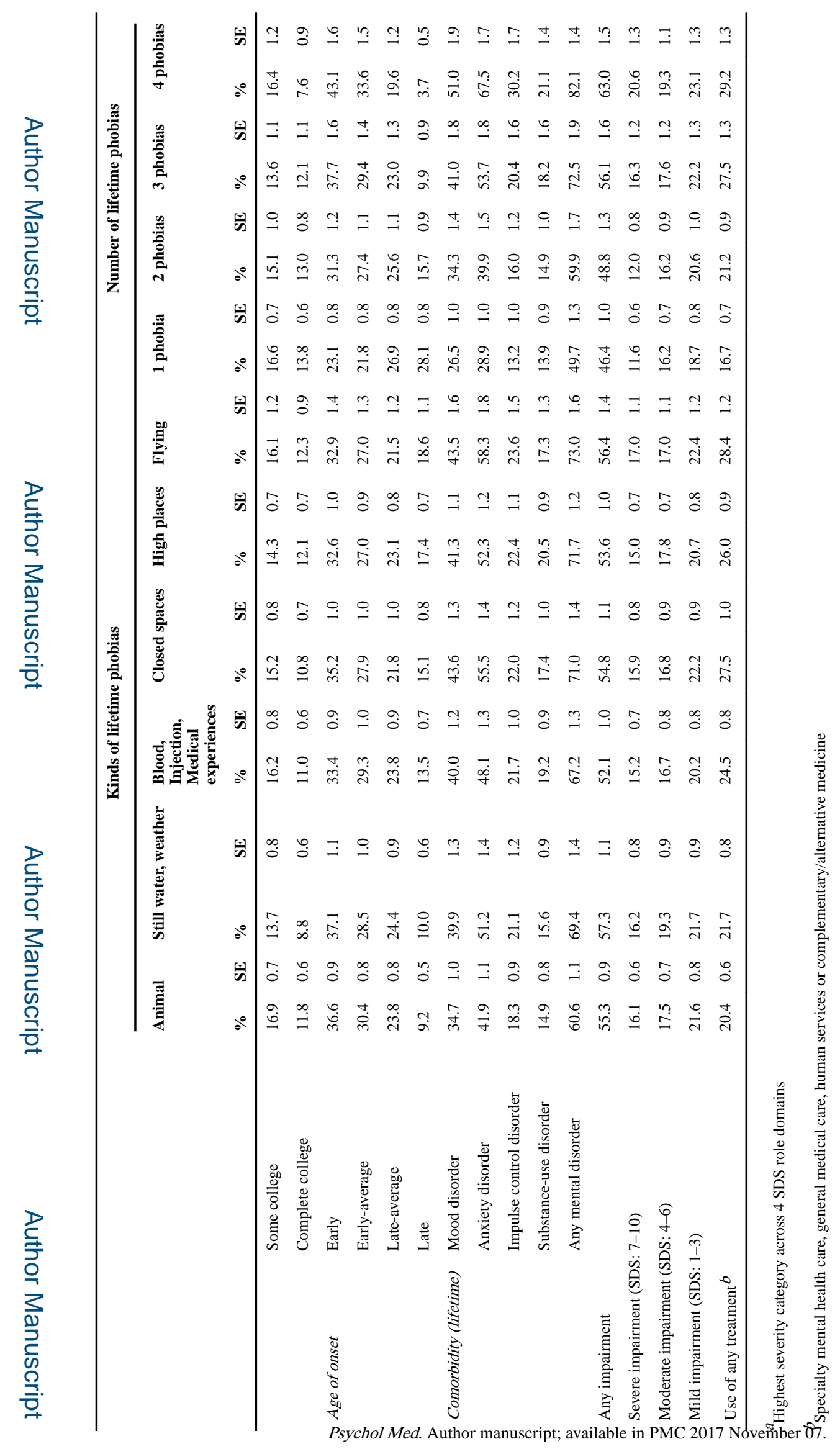




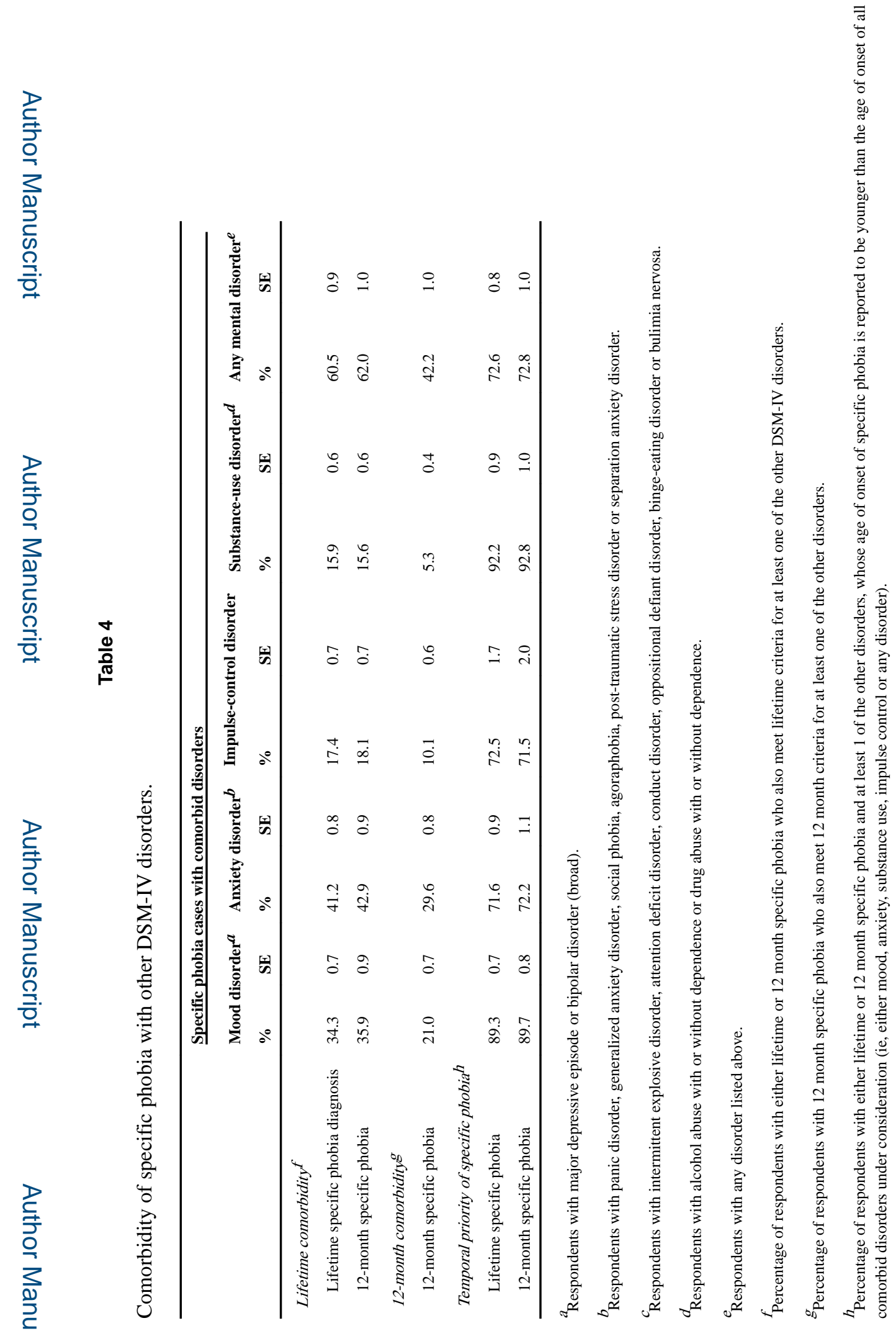

Psychol Med. Author manuscript; available in PMC 2017 November 07. 


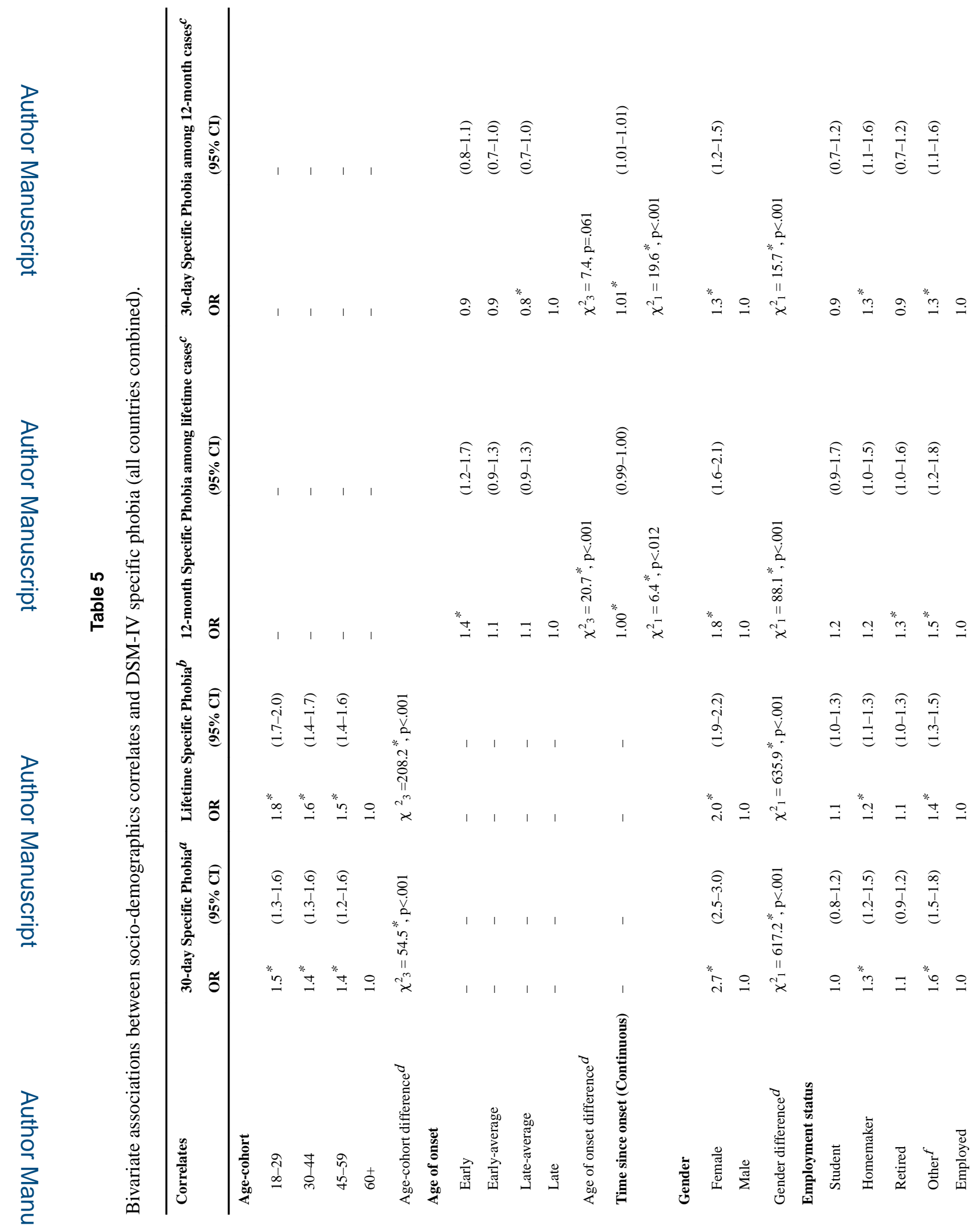


Wardenaar et al.

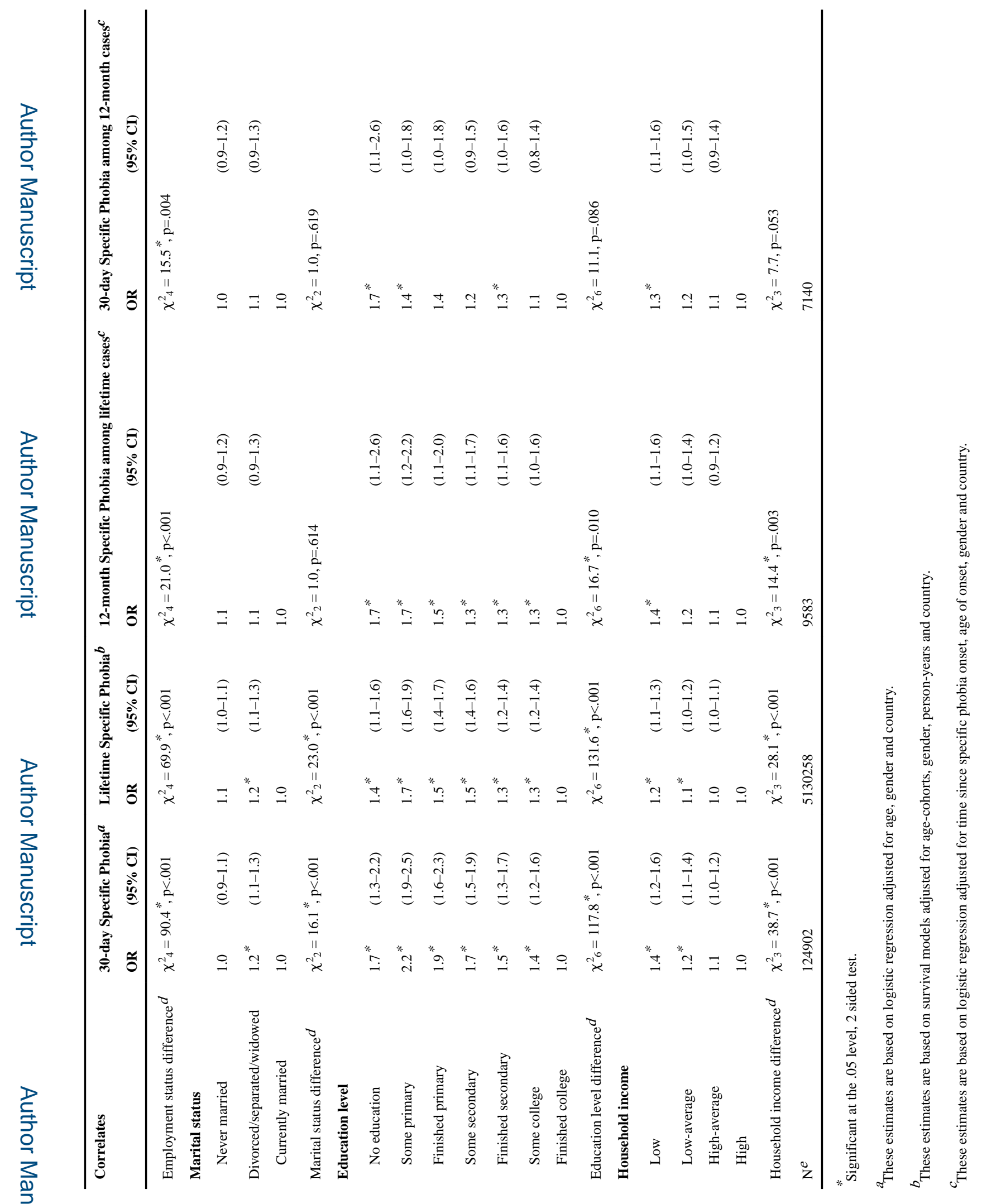


Wardenaar et al.

Page 36

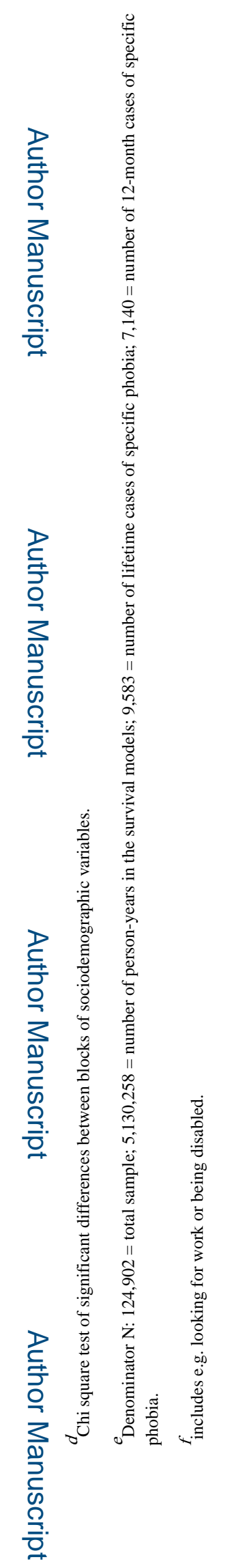

Psychol Med. Author manuscript; available in PMC 2017 November 07. 